BLAY GIL, Ester; VARONA GÓMEZ, Daniel: “El castigo en la España del siglo XXI.

Cartografiando el iceberg de la penalidad".

Polít. Crim. Vol. 16, No 31 (Junio 2021), Art. 5, pp. 115-145

[http://politcrim.com/wp-content/uploads/2021/04/Vol16N31A5.pdf]

\title{
El castigo en la España del siglo XXI. Cartografiando el iceberg de la penalidad*
}

\section{Punishment in Spain in the 21rst Century. Drafting the cartography of the iceberg of penality}

\author{
Ester Blay Gil \\ Profesora agregada, Facultad de Derecho, Universidad de Girona \\ ester.blay@udg.edu \\ https://orcid.org/0000-0002-5523-0140 \\ Daniel Varona Gómez \\ Catedrático, Facultad de Derecho, Universidad de Girona \\ daniel.varona@udg.edu \\ https://orcid.org/0000-0002-8677-2137
}

\section{Resumen}

Fecha de recepción: 19/03/2020.

Fecha de aceptación: 22/10/2020.

El debate acerca del populismo punitivo se ha centrado en España en la evolución legislativa y las modificaciones que en los últimos 25 años han ido endureciendo las respuestas penales a la delincuencia. Adicionalmente, se ha prestado atención al crecimiento de la población penitenciaria como señal de abuso del sistema penal. Estas líneas de investigación, sin embargo, resultan incompletas si lo que se pretende es conocer la realidad penológica en nuestro país, pues los datos oficiales no tienen en cuenta las posibilidades existentes de suspensión y sustitución de las penas de prisión. Este artículo busca acercarse a dicha realidad penológica presentando los resultados descriptivos de una investigación centrada en la aplicación judicial de las penas. A diferencia de lo que sucede con las estadísticas oficiales, al tener en cuenta la decisión judicial relativa a la suspensión y sustitución de la pena de prisión, se presenta aquí una cartografía más completa de las penas efectivamente ejecutadas. En última instancia, los resultados de esta investigación revelan un amplio recurso a las alternativas a prisión, en un contexto de crecimiento global del sistema penal.

Palabras clave: Penas, aplicación judicial de las penas, prisión, suspensión de la pena.

\footnotetext{
* Agradecemos a todos los jueces y juezas de lo penal, letradas y letrados de la Administración de Justicia y personal de los diversos juzgados en los que se ha desarrollado esta investigación por su ayuda y colaboración durante el trabajo de campo. Esta investigación ha sido realizada en el contexto del proyecto de investigación "La discrecionalidad en la elección y ejecución del castigo" (PGC2018-099155-B-I00), financiado por el Ministerio de Ciencia, Innovación y Universidades, y el grupo de investigación reconocido por la Agencia de Gestión de Ayudas Universitarias y de Investigación de la Generalitat catalana Justicia penal y democracia (2017 SGR 1607).
} 


\begin{abstract}
The debates around popular punitivism in Spain have focused on the Penal Code's legal reforms over the last 25 years, which have harshened penal responses to crime. Additionally, scholars have resorted to the rise of prison population and prison rates as a sign of overuse of the criminal justice system. However, these studies are not enough to reveal a complete picture of the sentencing alternatives used by judges, which includes suspended and substituted prison sentences that do not appear in official statistics. This paper contributes to this debate by presenting the descriptive results of a study on the judicial application of the sentencing alternatives. Contrary to the collection of official statistics, this paper considers the discretionary decision to suspend and substitute prison sentences, presenting a more complete picture of sentencing in Spain. The results of this research show judges resort considerably to alternatives to prison, in a context of overall growth of the criminal justice system.
\end{abstract}

Keywords: sanctions, sentencing, prison, suspended sentences.

\title{
Introducción
}

Como es bien conocido, uno de los tópicos "estrella" en el debate penal y criminológico actual es el relativo a la evolución de los sistemas punitivos. En esta línea, expresiones como "populismo punitivo", "expansión del Derecho Penal", "' "nuevo modelo penal de la seguridad ciudadana"" o "cultura del control", ${ }^{4}$ se han popularizado para definir la política criminal contemporánea a la vez que han sido objeto de una intensa discusión académica en los últimos años. ${ }^{5}$

En España existe una abundante literatura que ha tratado de dar cuenta del fenómeno en cuestión, y que prácticamente es unánime a la hora de reconocer en nuestra propia evolución punitiva los rasgos del populismo (o giro) punitivo y el, parafraseando el título de un reciente trabajo de Díez Ripollés, ${ }^{6}$ "abuso del sistema penal".

Sin embargo, tanto en España como en general en otros países, el diagnóstico sobre la evolución del Derecho Penal se ha realizado fundamentalmente sobre la base del estudio de la actividad legislativa; esto es, analizando mayormente los procesos de creación o

${ }^{1}$ BOTTOMS (1995), p. 17.

${ }^{2}$ SILVA SÁNCHEZ (2001), passim.

${ }^{3}$ DÍEZ RIPOLLÉS (2004), passim.

${ }^{4}$ GARLAND (2001) passim.

${ }^{5}$ En particular se ha debatido la propia existencia de un "giro punitivo" (punitive turn) en los países occidentales (clásico en este punto es el trabajo crítico de MATTHEWS (2005), pp. 321 -343; y en aquellos donde se ha identificado tal evolución se ha reflexionado arduamente sobre las causas o determinantes de dicho proceso.

${ }^{6}$ DÍEZ RIPOLLÉS (2017), passim.

${ }^{7}$ Sin ánimo de exhaustividad puede consultarse SILVA SÁNCHEZ (2001), passim; DÍEZ RIPOLLÉS (2004), passim; LARRAURI PIJOAN (2009), passim; DEL ROSAL BLASCO (2009), passim; GONZÁLEZ SÁNCHEZ (2011), passim. No obstante, debe señalarse que el reciente descenso de la población penitenciaria en España parece estar reconfigurando algunos discursos (véase BRANDARIZ GARCÍA (2014), pp. 309-342 y BRANDARIZ GARCÍA (2018), pp. 308-328). 


\section{Polít. Crim. Vol. 16, № 31 (Junio 2021), Art. 5, pp. 115-145 [http://politcrim.com/wp-content/uploads/2021/04/Vol16N31A5.pdf]}

modificación de las leyes penales (criminalización de nuevas conductas o agravación de las consecuencias del delito). ${ }^{8}$ Este "enfoque legislativo" ha descuidado el análisis del impacto real de la evolución de las leyes penales en las prácticas concretas del castigo. Y, por lo menos en España, cuando se ha prestado atención al castigo, el foco ha sido usualmente el relativo a la evolución de la población penitenciaria. Ciertamente, esta preocupación por la prisión es comprensible debido a que estamos ante la sanción penal más severa y por ello el castigo paradigmático. Adicionalmente, estamos ante un castigo que resulta sencillo de analizar en cuanto a su evolución, ya que desde hace años las instituciones penitenciarias ofrecen estadísticas sobre la población reclusa.

Sin embargo, por muy útiles que sean los datos sobre evolución de la población reclusa para presentar una panorámica del sistema punitivo, en nuestro caso el español, con ello solo estamos en realidad contemplando la punta del iceberg, ${ }^{9}$ ya que existe investigación criminológica en nuestro país que demuestra que, afortunadamente, solo una minoría de los condenados por delito acaban finalmente en prisión. ${ }^{10}$

Por tanto, si nos centramos tan solo en las cifras sobre población penitenciaria, estaríamos magnificando el papel de la prisión en el sistema punitivo español, desconociendo con ello la gran parte del castigo que permanece, siguiendo con la metáfora del iceberg, oculto bajo las aguas. ${ }^{11}$

De hecho, la metáfora del iceberg es muy pertinente en el caso español pues, así como, según hemos dicho, tenemos datos oficiales longitudinales sobre población reclusa (que nos permiten así ver la parte superior del iceberg), tales datos no existen cuando se trata de completar el panorama de la penalidad en España, por lo que el resto de las penas queda sumergido y, así, no visible. Ello se debe a una importante carencia que presentan los datos oficiales españoles sobre penas. En este trabajo se presentan los resultados generales de una investigación basada en el análisis de datos procedentes de juzgados de lo penal que busca precisamente contribuir a superar esta carencia.

En un primer apartado se presentan las características generales del sistema de penas español. Seguidamente, se discuten las limitaciones de los datos oficiales sobre la imposición de las penas, que por sí mismas justifican la necesidad de estudios como el presente. En un tercer apartado se exponen los resultados de los estudios que han buscado suplir las carencias de

\footnotetext{
${ }^{8}$ Paradigmático en este sentido en España el estudio de DÍEZ RIPOLLÉS (2013a), passim y DÍEZ RIPOLLÉS (2013b), passim.

${ }^{9}$ Tradicionalmente la metáfora del iceberg se ha empleado en criminología en relación con la delincuencia. En este sentido, ver por ejemplo el uso que hacen de la misma REDONDO y GARRIDO (2013), passim. En este trabajo, sin embargo, la metáfora se emplea de forma distinta, cambiando de sentido para referirse únicamente a la penalidad: el área visible del iceberg es la penalidad que los datos oficiales permiten observar, mientras que el área sumergida del iceberg responde a las formas de castigo estadísticamente invisibles. Únicamente la consideración del conjunto del iceberg/penalidad permite tener una idea de la imposición de penas en España.

${ }^{10}$ Sabemos que España posee una de las tasas de entrada en prisión más bajas de la Unión Europea (véase CID (2020), p. 3, que muestra que para 2017 esa tasa fue de 71 por 100.000 habitantes; lo que en atención a la población española ese año nos daría una cifra aproximada de 33.000 entradas a prisión en el año 2017, lo cual sería a su vez sobre un $12 \%$ de las condenas penales — según datos del INE en el año 2017 se dictaron en España 285.336 condenas por delito-).

${ }^{11}$ En la literatura criminológica española ha advertido sobre ello CID (2017), pp. 41-54.
} 
las estadísticas oficiales sobre la aplicación judicial del sistema de penas. La revisión de los datos oficiales y la literatura existente evidencia la necesidad de investigaciones con datos primarios para conocer cómo los jueces están aplicando el sistema de penas en la práctica. Después de explicitar los objetivos y metodología del presente estudio, se recogen sus principales resultados, distinguiendo el análisis entre del momento de imposición de la pena y el momento de ejecución, que recoge la decisión judicial acerca de la suspensión o la sustitución de las penas de prisión. Estos resultados muestran, como se refleja en el último apartado del artículo, un mapa de la penalidad más complejo de lo aparente.

\section{Breve referencia al sistema de penas en España}

Siguiendo la tradición codificadora, el Código Penal español (en adelante "CPE") describe las conductas delictivas y las sanciones a imponer como respuesta a las mismas. En la parte especial del CPE se recogen las penas a imponer en cada caso; puede tratarse de una pena única, ${ }^{12}$ de más de una pena a imponer por el juez de forma cumulativa, ${ }^{13}$ o de dos o más penas alternativas entre sí, debiendo el juez decidir en estos casos qué sanción es la más adecuada para el supuesto concreto. ${ }^{14}$ En ocasiones se recogen penas cumulativas y disyuntivas. $^{15}$

Las penas principales pueden ser (1) privativas de libertad, entre las que tiene un papel clave la prisión (art. 35 y ss. CPE); (2) penas de multa, privilegiándose en el Código el sistema de días multa o de multas por cuotas, por encima de las multas proporcionales (arts. $50 \mathrm{y} \mathrm{ss}$ CPE), y (3) las penas de trabajo en beneficio de la comunidad (en adelante, TBC; art. 49 $\mathrm{CPE}$ ). Estas últimas, por requerir para su imposición el consentimiento del penado, nunca se recogen como pena única, sino como pena alternativa a otra que se aplicará en los casos en que no se acepte la imposición del TBC, o cuando el juez lo estime adecuado ${ }^{16}$. Se establecen en los artículos de la parte especial del CPE los mínimos y máximos de las penas a imponer, y, en la parte general del CPE las circunstancias a valorar judicialmente para la determinación de la pena en supuestos concretos.

Además de las penas principales, la parte general del Código penal prevé la posibilidad de imponer penas accesorias (arts. 54 y ss. CPE), que sin poderse aplicar por sí mismas

\footnotetext{
${ }^{12}$ Las penas únicas pueden ser privativas de libertad o multas.

${ }^{13}$ Esto es lo que sucede, por ejemplo, en el caso del descubrimiento y revelación de secretos, en que el legislador prevé que su autor "será castigado con las penas de prisión de uno a cuatro años y multa de doce a veinticuatro meses" (art. 197.1 CPE).

${ }^{14}$ Este es el caso de las lesiones, que se castigan "con la pena de prisión de tres meses a tres años o multa de seis a doce meses" (art. 147.1 CPE).

${ }^{15}$ Esto es lo que ocurre, por ejemplo, en relación con los malos tratos ocasionales constitutivos de violencia de género, castigados "con la pena de prisión de seis meses a un año o de trabajos en beneficios de la comunidad de treinta y uno a ochenta días y, en todo caso, privación del derecho a la tenencia y porte de armas de un año y un día a tres años, así como, cuando el juez o tribunal lo estime adecuado al interés del menor o persona con discapacidad necesitada de especial protección, inhabilitación para el ejercicio de la patria potestad, tutela, curatela, guarda o acogimiento hasta cinco años" (art. 153.1 CPE).

${ }^{16}$ Esto sucede, por ejemplo, para el hurto de uso de vehículos a motor, infracción para la que se prevé que el autor que restituya el vehículo "será castigado con la pena de trabajos en beneficio de la comunidad de treinta y uno a noventa días o multa de dos a doce meses" (art. 244.1 CEP).
} 


\section{Polít. Crim. Vol. 16, ํo 31 (Junio 2021), Art. 5, pp. 115-145 \\ [http://politcrim.com/wp-content/uploads/2021/04/Vol16N31A5.pdf]}

acompañan siempre a las principales, generalmente consistentes en suspensiones y privaciones de derechos (art. 39 y ss. CPE).

Adicionalmente, el CPE establece las normas básicas de ejecución de las penas, referidas a su sustitución o suspensión, y la libertad condicional (art. 90 y ss. CPE) y el tercer grado (art. 36, 78 y 78 bis CPE). Así, el CPE, recoge la posibilidad de que las penas de prisión inferiores a dos años puedan ser suspendidas por los jueces en determinadas circunstancias, pudiéndose imponer obligaciones adicionales a la condición de no delinquir durante el periodo de suspensión (art. 80 y ss. CPE). Excepcionalmente, se permite la suspensión de penas de prisión de duración superior a los dos años y a personas con antecedentes penales (art. 80.3, 4 y 5 CPE). Por otra parte, se prevé la sustitución obligatoria de las penas de prisión inferiores a 3 meses (art. $71 \mathrm{CPE)} \mathrm{así} \mathrm{como} \mathrm{la} \mathrm{sustitución} \mathrm{por} \mathrm{expulsión} \mathrm{de} \mathrm{las} \mathrm{penas} \mathrm{de} \mathrm{prisión}$ impuestas a personas extranjeras en determinadas circunstancias (art. $89 \mathrm{CPE}$ ).

Esta breve descripción ya refleja que los jueces penales tienen cierto ámbito de discrecionalidad en la determinación de la pena aplicable y en el momento de decidir acerca de su ejecución. Para conocer cómo los jueces ejercen su discrecionalidad y, en definitiva, qué penas se están aplicando en la práctica de los juzgados y tribunales españoles, el primer paso es recurrir a las estadísticas oficiales de condenados.

\section{Los datos oficiales sobre la aplicación de las penas y sus limitaciones}

La principal fuente oficial sobre la aplicación de las penas es el Instituto Nacional de Estadística, que recoge los datos proporcionados por el Registro Central de Penados sobre penas impuestas en sentencia firme por los órganos judiciales españoles. ${ }^{17}$ Sin embargo, el problema que surge al recoger datos relativos a las penas impuestas en sentencia firme es que debe tenerse muy en cuenta que la pena impuesta en sentencia y la finalmente ejecutada puede ser bien distinta. Ello es debido a todas las posibilidades que se contemplan en la legislación penal española sobre suspensión y sustitución de penas. En particular, y por lo que respecta a la pena de prisión, los datos del Instituto Nacional de Estadística no permiten saber, del total de penas de prisión impuestas en sentencia, cuántas son finalmente ejecutadas y cuántas son, por el contrario, suspendidas.

Debe tenerse en cuenta que, como se ha mencionado, el CPE, la modalidad genérica de suspensión (art. 80.1 y 2 CPE), permite suspender las penas de prisión de hasta 2 años, y este tipo de penas representa precisamente el gran grueso de las penas de prisión impuestas en sentencia, tal y como puede observarse en la siguiente tabla:

\footnotetext{
17 Véase INE, Sociedad, Seguridad y https://www.ine.es/dyngs/INEbase/es/categoria.htm?c=Estadistica_P\&cid=1254735573206 [visitado el 22/02/2020].
} 
BLAY GIL, Ester; VARONA GÓMEZ, Daniel: “El castigo en la España del siglo XXI. Cartografiando el iceberg de la penalidad”.

Tabla 1: Duración de las penas de prisión impuestas en 2017 en España

\begin{tabular}{|l|c|c|}
\hline $\begin{array}{c}\text { Penas de prisión según } \\
\text { duración de la pena }\end{array}$ & (n) & $\mathbf{( \% )}$ \\
\hline Total & 145.494 & 92,95 \\
\hline De 0 a 2 años & 135.244 & 5,87 \\
\hline De más de 2 años a 5 años & 8.540 & 1,18 \\
\hline Más de 5 años & 1.710 & \\
\hline
\end{tabular}

Fuente: INE, Estadística de condenados 2017.

Si casi el 93\% de las penas de prisión impuestas son susceptibles de suspensión, para valorar la dimensión del castigo en España es necesario saber cómo los jueces están aplicando esta institución. En definitiva, para valorar la dimensión y evolución del castigo en un país determinado hemos de atender no únicamente a la legislación penal sino también a su aplicación práctica. Ello exige disponer de datos fiables sobre las penas, no meramente impuestas en sentencia, sino finalmente ejecutadas. Solo así podremos hacer una cartografía ajustada del iceberg de la penalidad.

Sin embargo, según decíamos, es precisamente respecto a las penas finalmente ejecutadas que existe una preocupante laguna de datos oficiales en España. Dicha laguna es además particularmente difícil de solventar, ya que, a falta de datos oficiales, al investigador no le queda más remedio que acudir a la fuente de datos, esto es, a los propios juzgados o tribunales penales para tratar de conocer cómo se ejecutan las penas impuestas en sentencia. Estas dificultades son las que quizá explican que la investigación existente solo parcialmente suple las limitaciones de los datos oficiales, como se reflejará en el siguiente apartado.

\section{Las investigaciones sobre el sistema de penas en España}

Como se ha mencionado, la mayor parte de las investigaciones sobre el sistema de penas en España han consistido en análisis legislativos y de la evolución del recurso a la prisión. ${ }^{18}$ Las investigaciones sobre la aplicación judicial del sistema de penas, sin embargo, son escasas y se basan, en su mayoría, en estadísticas oficiales. ${ }^{19}$

Entre estas investigaciones destaca la publicada por Morillas Cueva y Barquín Sanz en $2013 ;{ }^{20}$ en lo que nos interesa, su investigación sobre la aplicación de la suspensión se basa en datos obtenidos a través de una petición ad hoc al Registro Central de Penados acerca de las suspensiones concedidas entre los años 2008 y 2011. Los datos obtenidos muestran que mientras que en 2008 se suspendieron prácticamente la mitad de las penas de prisión impuestas, este porcentaje disminuye anualmente, suspendiéndose únicamente un $36 \%$ de las penas de prisión impuestas en 2011. Como ponen de manifiesto los propios autores, estos

\footnotetext{
${ }^{18}$ Ver notas al pie 6 a 8.

${ }^{19}$ Ver, por ejemplo, los trabajos de GIL et al. (2018), passim y NIETO et al. (2017), pp. 1-100. Para valorar la aplicación de la suspensión estos trabajos recurren únicamente a datos proporcionados por las administraciones responsables de la ejecución de las suspensiones con reglas de conducta y no recogen las suspensiones ordinarias, que son la amplia mayoría de las concedidas por los jueces españoles.

${ }^{20}$ MORILLAS CUEVA y BARQUÍN SANZ (dir.) (2013), pp. 217-221.
} 


\section{Polít. Crim. Vol. 16, № 31 (Junio 2021), Art. 5, pp. 115-145 [http://politcrim.com/wp-content/uploads/2021/04/Vol16N31A5.pdf]}

porcentajes son poco fiables, pues recogen únicamente las suspensiones que se deciden en la misma sentencia condenatoria, y no las que se han decidido en un auto posterior.

Ante las confusiones a las que puede llevar realizar investigaciones recurriendo únicamente a datos oficiales, es necesario revisar las investigaciones que trabajan con datos primarios. El acceso a datos primarios comporta en primer lugar una dificultad logística relacionada con el propio acceso a los datos. Este tipo de investigación requiere tener acceso directo a las denominadas "ejecutorias penales", esto es, a expedientes judiciales con todo tipo de información sobre el penado o penados. ${ }^{21}$ En este sentido, es comprensible el celo que en ocasiones existe entre los operadores judiciales ${ }^{22}$ a la hora de permitir el acceso a las ejecutorias por parte de investigadores. No es fácil, en definitiva, tener acceso a los datos necesarios para analizar el proceso de ejecución de las penas impuestas en sentencia. En segundo lugar, recoger datos primarios es considerablemente costoso si se quiere trabajar con muestras de ejecutorias representativas del conjunto de las decisiones que toman los tribunales: la recogida de los datos debe realizarse de los expedientes en papel, por parte de técnicos suficientemente formados y supervisados.

Estas dificultades son, seguramente, lo que explica que en España (hasta donde llega nuestro conocimiento) tan solo exista una investigación general (esto es, no reducida a un delito o delitos concretos ${ }^{23}$ ) que ha superado estos problemas y que por ello puede considerarse que nos proporcionan datos fiables sobre la ejecución de las penas en nuestro país. Se trata de la investigación coordinada en su día por Cid y Larrauri ${ }^{24}$ que, sobre la base de una muestra representativa de las ejecutorias de los Juzgados de lo Penal de Barcelona derivadas de sentencias impuestas en el año 1998, buscaba evidenciar cómo los jueces aplicaban su discrecionalidad en relación con el recurso a las alternativas a prisión en tres situaciones distintas: cuando el legislador prevé para una infracción concreta la posibilidad de imponer prisión o una alternativa (en ese momento, multa), en la decisión de suspender o sustituir una pena privativa de libertad impuesta en sentencia, y a la hora de reaccionar a los impagos de multa.

Los resultados de esta investigación muestran que (1) cuando los jueces pueden optar entre castigar una infracción con prisión y con una pena alternativa, recurren de forma mayoritaria a la segunda (en un 95\%); (2) en relación con las posibilidades sustitutivas o suspensivas, cabe distinguir dos situaciones: ante infractores sin antecedentes penales, los jueces recurren de forma cuasi automática a la suspensión de la pena; cuando los infractores tienen un

\footnotetext{
21 "Ejecutoria" es el nombre que recibe el expediente físico que recoge toda la documentación sobre un caso (desde su misma incoación, sea por atestado o denuncia, hasta la sentencia condenatoria firme) y que se abre formalmente en el Juzgado Penal competente para la ejecución una vez existe una condena penal firme por uno o más delitos a una o más personas.

22 En particular los denominados en España "Letrados y Letradas de la Administración de Justicia" (anteriormente llamados "Secretarios/as Judiciales"), como garantes de la Oficina Judicial.

${ }^{23}$ Existe alguna investigación con datos primarios referida a delitos concretos. En este sentido destaca ANTÓN y LARRAURI (2009), passim. Este trabajo, centrado en la aplicación judicial de la pena para los delitos de violencia doméstica ocasional (art. $153 \mathrm{CPE}$ ) muestra que, aunque los jueces recurren a la pena de prisión como respuesta privilegiada a este tipo de infracción, en la mayoría de los supuestos esta pena es posteriormente suspendida; el recurso a la prisión efectiva, pues, se reduce a una minoría de casos en la práctica.

${ }^{24}$ CID y LARRAURI (coord.) (2002), passim.
} 
historial penal, sin embargo, el recurso a la suspensión y la sustitución ${ }^{25}$ es minoritario; y (3) los jueces suspenden de forma mayoritaria la prisión impuesta como consecuencia del impago de una multa a personas sin antecedentes penales, pero no cuando los infractores tienen un historial penal; en estos casos, la ejecución de la prisión en caso de impago de multa es mayoritario. ${ }^{26}$

En lo que nos interesa en este trabajo, que son las penas definitivas impuestas a los infractores, la investigación liderada por Cid y Larrauri proporciona los datos que se reflejan a continuación:

Tabla 2: Penas definitivas impuestas a los infractores

\begin{tabular}{|l|l|l|}
\hline Tipo De Pena & $\mathbf{N}^{\mathbf{0}}$ Infractores-as & \% Infractores-as \\
\hline Prisión & 241 & $17 \%$ \\
\hline Arresto Fin Semana & 33 & $2.4 \%$ \\
\hline Arresto Domiciliario & 2 & $0.1 \%$ \\
\hline Trabajo Beneficio Comunidad & 0 & $0 \%$ \\
\hline Suspensión Pena Privativa De Libertad & 333 & $23.5 \%$ \\
\hline Multa & 809 & $57 \%$ \\
\hline Total & 1418 & $100 \%$ \\
\hline
\end{tabular}

Fuente: Cid y Larrauri (2002)

Después de la multa, la suspensión de la pena de prisión es la respuesta penal a la que más recurren los jueces, por encima de la prisión definitiva. Como puede observarse, pues, una investigación de este tipo es la única que puede presentar un panorama fiel de la imposición y ejecución de las penas, pues permite aflorar instituciones como la suspensión de la pena de prisión que obviamente resultan invisibles en los datos oficiales del INE.

Sin embargo, la cartografía del sistema punitivo obtenida con esta investigación presenta un problema fundamental: se basa, según hemos dicho, en datos de sentencias de hace más de 20 años, por lo que puede legítimamente dudarse de que ello responda a la realidad actual, máxime con la avalancha de reformas del Código Penal que se han sucedido en estos años. ${ }^{27}$

${ }^{25}$ En el momento en que se toman estas decisiones el CPE únicamente admite la suspensión de penas para personas sin antecedentes penales vivos (art. 81 CPE, en su readacción original por la Ley Orgánica 10/1995, de 23 de noviembre, del Código penal); para personas con antecedentes penales puede recurrirse a la suspensión cuando el infractor es drogodependiente (art. 87 CPE, en su redacción original por la Ley Orgánica 10/1995) o a la sustitución de penas de prisión por multa o arresto de fin de semana (antiguo art. $88 \mathrm{CPE}$, en su redacción original por Ley Orgánica 10/1995, actualmente derogado).

${ }^{26}$ CID y LARRAURI (coord.) (2002), passim.

${ }^{27}$ Desde su promulgación en 1995, el vigente Código penal ha experimentado numerosas modificaciones, muchas de ellas de directa incidencia en el sistema de penas. Así, cabe de destacar la Ley Orgánica 15/2003, que suprime la pena de arresto de fin de semana, introduce la localización permanente, modifica sustancialmente la regulación del TBC e introduce la posibilidad de sustituir penas de prisión impuestas a personas con antecedentes penales por multa o trabajos en beneficio de la comunidad (Ley Orgánica 15/2003, de 25 de noviembre, por la que se modifica la Ley Orgánica 10/1995, de 23 de noviembre, del Código Penal. Boletín Oficial del Estado núm. 283, de 26 de noviembre de 2003). Disponible en: https://www.boe.es/buscar/doc.php?id=BOE-A-2003-21538 [visitado el 22/02/2020]. La Ley Orgánica 1/2004 


\section{Polít. Crim. Vol. 16, № 31 (Junio 2021), Art. 5, pp. 115-145 \\ [http://politcrim.com/wp-content/uploads/2021/04/Vol16N31A5.pdf]}

Es por esta razón que los autores del presente trabajo diseñaron y coordinaron una investigación que pretende replicar la coordinada en su día por Cid y Larrauri, intentando así revelar una cartografía actual del iceberg de la penalidad española.

\section{Objetivos y metodología}

Como hemos explicitado en la introducción, el objetivo general de nuestra investigación es presentar una cartografía actual del sistema punitivo español. Junto a ello un objetivo adicional de este trabajo es comparar los datos obtenidos en nuestra investigación con los correspondientes a la ya mencionada investigación dirigida por Cid y Larrauri en 2002, tratando de trazar así cuál ha sido la evolución del sistema punitivo español en términos de las penas efectivamente aplicadas.

Para alcanzar estos objetivos y realizar una cartografía lo más fidedigna posible del sistema punitivo español, en nuestra investigación tuvimos que tomar una serie de decisiones metodológicas. La primera decisión metodológica fue centrar nuestra investigación en los juzgados de lo penal. Estos son los órganos que procesan el grueso de la delincuencia conocida por el sistema de justicia penal, especialmente si atendemos a los datos sobre ejecución ${ }^{28}$; y los que por otra parte disponen de un mayor margen de discrecionalidad a la

obliga a imponer en supuestos de violencia de género reglas de conducta en todas las suspensiones (Ley Orgánica 1/2004, de 28 de diciembre, de Medidas de Protección Integral contra la Violencia de Género. Boletín Oficial del Estado núm. 313, de 29 de diciembre de 2004. Disponible en: https://www.boe.es/buscar/doc.php?id=BOE-A-2004-21760 [visitado el 22/02/2020]). Ley Orgánica 15/2007 modifica las penas a imponer para algunos de los delitos más importantes contra la seguridad vial, permitiendo al juez optar entre prisión o multa y TBC (Ley Orgánica 15/2007, de 30 de noviembre, por la que se modifica la Ley Orgánica 10/1995, de 23 de noviembre, del Código Penal en materia de seguridad vial. Boletín Oficial del Estado, núm. 288. Disponible en: https://www.boe.es/buscar/doc.php?id=BOE-A-2007-20636 [visitado el 22/02/2020]); la Ley Orgánica 5/2010 vuelve a modificar la penalidad de la seguridad vial, además de regular la responsabilidad penal de las personas jurídicas (Ley Orgánica 5/2010, de 22 de junio, por la que se modifica la Ley Orgánica 10/1995, de 23 de noviembre, del Código Penal. Boletín Oficial del Estado núm. 152, de 23 de junio de 2010. Disponible en: https://www.boe.es/diario boe/txt.php?id=BOE-A-2010-9953 [visitado el 22/02/2020], y más recientemente la Ley Orgánica 1/2015 suprime las faltas, introduce la prisión permanente revisable en el catálogo de penas y modifica, en lo que nos interesa, la regulación de la sustitución de la pena por expulsión y suspensión, facilitando su aplicación a personas con antecedentes y subsumiendo la antigua sustitución en esta institución (Ley Orgánica 1/2015, , de 30 de marzo, por la que se modifica la Ley Orgánica 10/1995, de 23 de noviembre, del Código Penal. Boletín Oficial del Estado núm. 77, de 31 de marzo de 2015. Disponible en: https://www.boe.es/diario_boe/txt.php?id=BOE-A-2015-3439 [visitado el 22/02/2020].

${ }^{28}$ Las leyes procesales españolas (art. 89 bis Ley Orgánica del Poder Judicial y 14.3 Ley de Enjuiciamiento Criminal) atribuyen a los denominados Juzgados de lo Penal el enjuiciamiento y fallo de las causas por delitos a los que la ley señale una pena privativa de libertad igual o inferior a 5 años, aunque, si en un único juicio, por razones de conexidad o continuidad delictiva, se enjuician simultáneamente varios delitos con penas individuales inferiores a 5 años pero superiores a los 5 años en su acumulación material, la competencia seguirá correspondiendo a los Juzgados de lo penal. Por otra parte, los Juzgados de lo Penal ejecutan todas las sentencias dictadas por ellos mismos y por los Juzgados de Instrucción de su demarcación en los juicios que finalizan con sentencia de conformidad "premiada" (en el Juzgado de Instrucción que realiza funciones de Juzgado de Guardia, véase art. 801.1. Ley de Enjuiciamiento Criminal). La conformidad "premiada" es la que se presta ante el propio Juzgado de Guardia en los casos de procedimientos de Diligencias Urgentes y conlleva la imposición de la pena solicitada por el Ministerio Fiscal "reducida en un tercio, aun cuando suponga la imposición de una pena inferior al límite mínimo previsto en el Código Penal" (art. 801.2 Ley de Enjuiciamiento Criminal). Ley Orgánica 6/1985, de 1 de julio, del Poder Judicial. Boletín Oficial del Estado núm. 157. Disponible en: https://www.boe.es/buscar/act.php?id=BOE-A-1985-12666 [visitado el 22/02/2020]. Real 
hora de ejecutar la pena impuesta en sentencia, pues en la mayoría de los casos imponen penas susceptibles de ser suspendidas o sustituidas. Además, estos juzgados tienen encomendada la ejecución de las penas impuestas por los Juzgados de Instrucción o de Primera Instancia e Instrucción, salvo en los supuestos de delitos leves.

Centrada nuestra investigación en los Juzgados de lo Penal, la segunda decisión metodológica fue la relativa a qué o cuántos Juzgados de lo Penal debíamos tomar como objeto de investigación para poder trazar un panorama fidedigno del sistema punitivo español. Evidentemente, lo ideal en términos metodológicos hubiera sido calcular una muestra significativa de los 383 Juzgados de lo Penal existentes en España en 2015 y $2016^{29}$ para después realizar una asignación aleatoria entre los mismos, y posteriormente presentarnos en los Juzgados de lo Penal finalmente escogidos para realizar la investigación. Pero este ideal metodológico era inviable en atención a la capacidad del grupo investigador.

Por esta razón se realizó una elección de conveniencia de las demarcaciones judiciales objeto de nuestra investigación. En concreto, los Juzgados de lo Penal escogidos para seleccionar la muestra de ejecutorias son Girona y Barcelona, lugares de residencia de los autores del presente artículo y responsables de la investigación. Más allá de esta razón de conveniencia, la elección de las dos sedes judiciales corresponde a la voluntad de recoger muestras de los dos modelos de ejecución existentes en el sistema judicial español: el centralizado y el descentralizado. Girona es una capital de provincia, de aproximadamente 100.000 habitantes, que puede considerarse una ciudad española tipo en la que la ejecución de las sentencias penales es atribuida al propio juzgado sentenciador (Juez de lo Penal). ${ }^{30}$

Por su parte, Barcelona es una de las grandes ciudades españolas en las que, para responder al volumen de sentencias a ejecutar, se han especializado cuatro Juzgados de lo Penal en la ejecución de las sentencias, los llamados Juzgados de Ejecutorias. Como hemos mencionado, estos Juzgados únicamente ejecutan las sentencias dictadas por los Jueces de lo Penal (o de Instrucción, o Primera Instancia e Instrucción) de su demarcación judicial, sin realizar labores

Decreto de 14 de septiembre de 1882 por el que se aprueba la Ley de Enjuiciamiento Criminal. Boletín Oficial del Estado núm. 260. Disponible en: https://www.boe.es/buscar/act.php?id=BOE-A-1882-6036 [visitado el 22/02/2020].

A modo de ilustración de la distribución de asuntos entre órcanos de la jurisdicción penal, de acuerdo con los datos del Consejo General del Poder Judicial, en 2016 se dictaron 644.693 sentencias penales y se resolvieron 537.323 asuntos en ejecución. Los Juzgados de Instrucción y de $1^{\text {a }}$ Instancia e Instrucción dictaron el 57,36\% de las sentencias y resolvieron el 22,21\% de los asuntos en ejecución; los Juzgados de lo Penal dictaron el $25,8 \%$ de las sentencias de lo penal y resolvieron el 54,6\% de los asuntos en ejecución. Por su parte, las Salas de lo Penal de las Audiencias Provinciales dictaron el 9,84\% de las sentencias de lo penal y resolvieron un 3,4\% de los asuntos en ejecución (CONSEJO GENERAL DEL PODER JUDICIAL (2016), passim. Disponible en: http://www.poderjudicial.es/cgpj/es/Temas/Estadistica-Judicial/Estudios-e-Informes/Justicia-Dato-a-Dato/ [visitado el 22/02/2020]).

${ }^{29}$ Datos procedentes de los informes correspondientes a 2015 y 2016 elaborados por el Consejo General del Poder Judicial, Situación de la demarcación y planta judicial. El dato corresponde a los juzgados efectivamente constituídos; los legalmente previstos son unos pocos más. Disponibles en http://www.poderjudicial.es/cgpj/es/Temas/Estadistica-Judicial/Estadistica-por-temas/Estructura-judicial-yrecursos-humanos--en-la-administracion-de-justicia/Planta-judicial-y-plantillas-organicas/Planta-judicial/ [visitado el 22/02/2020].

${ }^{30}$ Salvo en los casos de sentencias dictadas por los Juzgados de Instrucción en casos de conformidad "premiada" (véase supra nota 18). 


\section{Polít. Crim. Vol. 16, № 31 (Junio 2021), Art. 5, pp. 115-145 [http://politcrim.com/wp-content/uploads/2021/04/Vol16N31A5.pdf]}

de enjuiciamiento y sentencia. ${ }^{31} \mathrm{La}$ inclusión de las dos demarcaciones territoriales seleccionadas, por tanto, permite recoger muestras de ejecutorias procedentes de juzgados de ambos modelos: el modelo descentralizado de ejecución (Girona) y el modelo centralizado (Barcelona).

Adicionalmente, por lo que respecta a las características sociodemográficas de los jueces y juezas penales en ambas ciudades, no tenemos noticia de ninguna investigación que haya acreditado diferencias significativas entre el personal judicial de Girona y Barcelona y los jueces del resto de ciudades españolas, ya sea en referencia al género, clase social, ideología política o cualquier otro tipo de característica personal o social. Es por ello que, a nuestro entender, los resultados que derivan del estudio realizado, evidentemente con todas las cautelas que conlleva el hecho de no ser factible realizar una investigación con una muestra representativa de todos los Juzgados Penales del territorio, son indicativos del estado de cosas existente en nuestro país. De hecho, cuando diseñamos la presente investigación ya tuvimos en cuenta el problema de la posible falta de representatividad de la muestra, pero consideramos que la única variable importante que debíamos controlar era el modelo de ejecución de las sentencias penales (centralizado/descentralizado). Nuestra hipótesis es que esta diferente configuración del órgano encargado de la ejecución de la sentencia sí puede ser relevante a la hora de tomar las decisiones que requiere el proceso de ejecución. Por el contrario, la adscripción orgánica de un juez o jueza a un determinado partido judicial (en nuestro caso, Girona y Barcelona) creemos que no comporta ninguna diferencia significativa respecto del resto de jueces del territorio. ${ }^{32}$

En definitiva, a pesar que, según decimos, nuestra investigación se limita a dos ciudades españolas, tenemos buenas razones para sostener que las dinámicas de penalidad que observaremos en tales ciudades son representativas de la realidad penal española. ${ }^{33}$ Estas "buenas razones" vienen además sostenidas por algunos datos disponibles, en particular uno muy relevante referido al porcentaje de penas de prisión que se suspenden o sustituyen. Según veremos (apartado 5.2.2 de este trabajo) respecto a este porcentaje sí tenemos datos fiables a nivel nacional que, tras ponerse en relación, permiten hacer una estimación bastante

\footnotetext{
${ }^{31}$ Salvo error u omisión por nuestra parte existen actualmente 5 Juzgados de Ejecutorias en Madrid, 4 en Barcelona, 3 en Valencia, y 1 en Palma de Mallorca, Bilbao y San Sebastián (véase Informe de la Inspección del Consejo General del Poder Judicial en relación a la situación de los Juzgados Penales de Ejecutorias, mayo 2008. Disponible en: http://estaticos.elmundo.es/documentos/2008/05/06/ejecutorias.pdf [visitado el $22 / 02 / 2020]$.

${ }^{32}$ El sistema de acceso a la judicatura es único para toda España y sigue el sistema de oposición, el cual, de hecho, puede afirmarse que asegura una distribución aleatoria de los jueces por todo el territorio español, independientemente de su edad, género, ideología o clase social, ya que el destino concreto depende de la nota obtenida en los exámenes de acceso y de la aleatoria disponibilidad anual de plazas. Para una descripción del sistema de acceso a la judicatura en España ver BLAY GIL y GONZÁLEZ SÁNCHEZ (2020), pp. 113-126.

${ }^{33}$ Como hemos dicho, no creemos que los jueces y juezas de las ciudades elegidas sean diferentes del resto de jueces y juezas españoles. Aun así, se podría alegar que lo que podría ser diferente es el tipo de delincuencia o delincuente que se "procesa" en tales ciudades respecto del resto de territorio español. Ciertamente, no tenemos datos para contrarrestar esta hipótesis, pero creemos que la propia elección de ciudades que hemos realizado es un punto fuerte en este sentido, porque en nuestra muestra tenemos datos, tanto de una gran ciudad (Barcelona, con la problemática propia de las grandes ciudades turísticas españolas referidas a la delincuencia contra la propiedad), como de una ciudad de tamaño medio (Girona, con una problemática delincuencial más diversa).
} 
aproximada del mismo, y que es coincidente con el resultado obtenido en nuestra investigación.

Por último, la tercera decisión metodológica tomada tiene que ver con el universo de asuntos analizados. Es virtualmente imposible tener acceso y analizar todas las ejecutorias penales que se gestionan en un juzgado penal. Por ello, el investigador debe planificar cuidadosamente su trabajo: (1) debe elegir el "universo" (o "población") a estudiar, tanto geográfica como temporalmente: queremos investigar las decisiones de " $\mathrm{x}$ " en el momento "t". (2) Conocido el total de unidades a estudiar ("universo"), ante la imposibilidad material de analizar todas ellas, debe seleccionarse una "muestra representativa" del total. Como su nombre indica la "muestra representativa" está configurada por el total de unidades que deben analizarse para poder ser considerada una representación estadísticamente fiable del total ("universo"). En ciencias sociales se utilizan fórmulas estadísticas para calcular dicha muestra representativa, por lo que el investigador deberá explicitar la calidad estadística de la muestra finalmente escogida (en función de sus posibilidades materiales), en el sentido de la potencia probabilística que posee para obtener inferencias respecto al universo total.

En este sentido, el planteamiento de nuestra investigación fue analizar una muestra representativa de las ejecutorias correspondientes a los años 2015 y 2016. Se escogieron estos dos años para poder valorar los posibles efectos de la relevante reforma llevada a cabo por la LO 1/2015 en el ámbito de la suspensión y sustitución de la pena. Para ello decidimos seleccionar como universo de la muestra todas las ejecutorias ingresadas en el primer semestre de cada año en las dos ciudades escogidas.

El instrumento para el análisis de las ejecutorias consistió en una plantilla elaborada ex profeso por el grupo de investigación, en la que se recogen todos los datos de interés de la misma. ${ }^{34}$ Para la elaboración de la plantilla se partió de la elaborada para la investigación coordinada por Cid y Larrauri, ${ }^{35}$ añadiéndole toda una serie de ítems de interés. La plantilla fue testada por los investigadores en una investigación piloto realizada entre los meses de abril y julio de 2014 en los Juzgados de Ejecutorias de Barcelona (sobre una muestra de 200 ejecutorias correspondientes al año 2012 y seleccionadas aleatoriamente).

En la siguiente tabla se refleja el universo de ejecutorias en ambos partidos judiciales y periodos de tiempo y la selección finalmente analizada en esta investigación.

\footnotetext{
${ }^{34}$ La plantilla recoge: 1) datos de identificación del expediente judicial; 2) datos sobre el penado (socio demográficos y judiciales); 3) datos sobre los delitos y penas solicitadas por la acusación e impuestas en sentencia (aunque limitamos la recogida de datos a los dos delitos más importantes por los que un penado era condenado); 4) datos sobre la ejecución de la pena de cada uno de los delitos por los que el penado era condenado (aunque analizamos únicamente la ejecución de las penas principales de prisión, localización permanente, multa y TBC). Se rellenaba una plantilla por cada condenado en sentencia, por lo que es mayor el número de expedientes recopilados que el de ejecutorias. La plantilla está disponible bajo demanda (anonimizado)

${ }^{35}$ CID y LARRAURI (2002), passim.
} 
Tabla 3: Resumen del conjunto de la muestra

\begin{tabular}{|l|l|l|l|}
\hline & $\begin{array}{l}\text { Total de } \\
\text { ejecutorias } \\
\text { ingresadas }\end{array}$ & $\begin{array}{l}\text { Muestra } \\
\text { ejecutorias } \\
\text { analizada }\end{array}$ & $\begin{array}{l}\text { Expedientes } \\
\text { analizados (n. de } \\
\text { penados) }\end{array}$ \\
\hline Girona 2015 & 1419 & 549 & 582 \\
\hline Girona 2016 & 1635 & 573 & 624 \\
\hline Barcelona 2015 & 6760 & 774 & 869 \\
\hline Barcelona 2016 & 7284 & 762 & 884 \\
\hline Total & 17098 & 2658 & 2959 \\
\hline
\end{tabular}

Los Juzgados de lo Penal de Girona ${ }^{36}$ tramitaron un total de 1419 ejecutorias durante el primer semestre de 2015, de las cuales el grupo investigador analizó ${ }^{37} 549$, equivalente a 582 expedientes individuales, pues cada ejecutoria puede corresponder a más de una persona penada y cada expediente en nuestra investigación corresponde a una persona. Las ejecutorias ingresadas en los Juzgados de lo Penal de Girona el primer semestre de 2016 fueron 1.635, de las que se analizaron 573, correspondientes a 624 expedientes individuales. El margen de error de las muestras obtenidas, para un nivel de confianza del $95 \%$ y $\mathrm{P}=\mathrm{Q}$, es de $\pm 3,3 \%$. La forma de selección de las ejecutorias finalmente analizadas fue aleatoria en cada juzgado ${ }^{38}$, aunque se realizó una afijación proporcional entre los diversos juzgados puesto que el número de ejecutorias de cada juzgado era diferente. ${ }^{39}$ La recogida de datos, en diversas fases, se realizó entre octubre de 2016 y abril de 2018.

Los Juzgados de Ejecutorias de Barcelona ${ }^{40}$ ingresaron un total de 6.760 ejecutorias en el primer semestre de 2015, de las que se analizaron 774, correspondientes a 869 expedientes individuales. Durante el primer semestre de 2016 se tramitaron 7.284 ejecutorias nuevas, de las que se analizaron 762 ejecutorias, correspondientes a 841 personas penadas. Inicialmente y para seleccionar la muestra, para cada período y juzgado se realizó una afijación fija de 200 ejecutorias por periodo y juzgado $(n=1.600)$ pues en Barcelona el número de ejecutorias tramitado por cada Juzgado es similar, con una selección de casos aleatoria simple,

\footnotetext{
${ }^{36}$ En Girona capital existen 6 Juzgados de lo Penal. El Juzgado Penal núm. 6 es exclusivo de delitos de violencia de género.

${ }^{37}$ El grupo investigador en Girona estuvo formado, al margen de por el firmante de este trabajo, por Cristina Vasilescu, Marc H. Vallès, Raluca Balan, Marcos del Río, Bernat Pladevall, Alba Viñas y Judit López. A todos ellos les quisiéramos expresar nuestro más sincero agradecimiento pues sin su colaboración la presente investigación habría sido imposible.

${ }^{38}$ En concreto, en Girona se escogieron al azar 4 o 5 números correlativos diferentes en cada Juzgado (dependiendo del tamaño de la muestra representativa) y se analizaron todas las ejecutorias acabadas en dichos números. A su vez, en cada Juzgado y por lo que respecta a las muestras de 2015 y 2016 se modificaron los números correlativos. De tal manera que, por ejemplo, si en el Juzgado de lo Penal núm. 1 se analizaron todas las ejecutorias del primer semestre de 2015 acabadas en 1, 2, 3 y 4, para el año 2016 las analizadas fueron las terminadas en 5, 6, 7 y 8. Con ello evitábamos analizar ejecutorias tramitadas solo por determinado personal de la oficina judicial (pues el personal administrativo de la oficina judicial se divide la gestión de las ejecutorias por el número en el que finalizan) tratando así de evitar cualquier sesgo "personal" en la tramitación de la ejecutoria.

${ }^{39}$ En particular, la diferencia más significativa es el número de ejecutorias tramitadas en el Juzgado Penal especializado en violencia de género, que era menos de la mitad que en los otros Juzgados.

${ }^{40}$ Los Juzgados con funciones exclusivas en ejecución o Juzgados de Ejecutorias son los Juzgados de lo Penal números 12, 15, 21 y 24 de Barcelona.
} 
empleando para ello el programa informático Excel. El margen de error de la muestra obtenida, para un nivel de confianza del $95 \%$ y $\mathrm{P}=\mathrm{Q}$, es de $\pm 2,36 \%$. La recogida de datos se desarrolló por el equipo de investigación ${ }^{41}$ en los despachos multiusos de cada uno de los Juzgados de Ejecutorias entre octubre de 2016 y julio de 2018.

En el siguiente apartado se describen las características de la muestra de ejecutorias analizadas (características sociodemográficas de las personas penadas, delitos cometidos, historial penal, aspectos procesales, etc.). Posteriormente se presenta un análisis descriptivo de las penas impuestas por los jueces, así como de las definitivamente ejecutadas. En la medida de lo posible, se comparan las características de la muestra y los datos sobre penas impuestas con los obtenidos a partir de la muestra de 1998.

\section{Resultados}

\subsection{Descripción de la muestra}

\subsubsection{Características sociodemográficas de la muestra}

La muestra de expedientes finalmente analizados corresponde a 2.959 personas. Como refleja la Tabla 4, el $87,3 \%$ de las mismas son hombres y el $12,7 \%$ mujeres. ${ }^{42}$ Por su parte, el $62,4 \%$ de la muestra corresponde a personas con la nacionalidad española y el 37,6\% a personas con una nacionalidad distinta. ${ }^{43}$

\footnotetext{
${ }^{41}$ El equipo de investigación estuvo formado, al margen de Ester Blay, por Ariadna Blanco, Tadeo Luna de la Mora, Marcela Cordero, Judith López, Daniela Montecino, Natalia Ojeda, José Andrés Pacheco, Juliana Sotelo y Guillermina Torno. A todos ellos muchas gracias por su colaboración. Queremos agradecer también la ayuda de Nahia Zorrilla Martínez en la elaboración de una primera versión de la plantilla empleada para la extracción de datos. A nivel general merece una mención especial Marc Juanola, que se encargó de traspasar la información de todos los expedientes, tanto de Girona como Barcelona, a la base de datos creada ex profeso para la investigación en el programa estadístico SPSS. Por último, agradecemos también a Ignacio González Sánchez su ayuda en los cálculos estadísticos de las muestras de la investigación, tanto en Girona como en Barcelona. 42 De acuerdo con la estadística de condenados del INE las mujeres representan un porcentaje todavía mayor de las personas condenadas: un 14,35\% de las mismas en 2015 y un 19,24\% en 2016.

${ }^{43}$ El porcentaje de personas extranjeras entre los condenados no coincide con el correspondiente al Instituto Nacional de Estadística para los años de la muestra: 23,35\% en 2015 y 23,2 en 2016. Una parte de la explicación de la sobre-representación de las personas extranjeras entre los condenados de la muestra puede deberse a que Catalunya es la comunidad autónoma en la que en 2015 y 2016 vivían más personas extranjeras (un 21,7\% y un 22,17\% del total de personas extranjeras en España vivían en esos dos años en Catalunya: más de un millón de los aproximadamente cuatro millones y medio de personas). Sobre la necesidad de abordar científicamente la relación que comúnmente se establece entre delincuencia e inmigración ver, por todos, GARCÍA ESPAÑA (2019), pp. 194-205.
} 
Tabla 4: Composición sociodemográfica de la muestra

\begin{tabular}{|l|l|l|l|l|l|l|}
\hline & Españoles & Españoles \% & Extranjeros & Extranjeros \% & Total & Total \% \\
\hline Hombres & 1591 & $61,6 \%$ & 992 & $38,4 \%$ & $2583 *$ & $87,3 \%$ \\
\hline Mujeres & 256 & $68,1 \%$ & 120 & $31,9 \%$ & 376 & $12,7 \%$ \\
\hline Total & $1847 * *$ & $62,4 \%$ & 1112 & $37,6 \%$ & 2959 & $100 \%$ \\
\hline
\end{tabular}

*Los 3 infractores respecto de los que no se ha podido identificar el sexo se clasifican como hombres españoles. ${ }^{44}$

** La persona cuya nacionalidad no ha podido determinarse se ha contabilizado como hombre español.

Esta descripción apunta a un notable aumento de la presencia de personas extranjeras en el conjunto de penados, que representaban únicamente un 7,9\% de la muestra de 1998, y a un menor, pero también claro, aumento de la delincuencia femenina, que suponía un 7,2\% del total en 1998. El aumento de personas extranjeras coincide con la llegada de un gran número de personas migrantes a España a partir de 1999/2000; entre 2000 y 2010 ingresaron unos 5 millones de personas extranjeras en la población, cifra que se estabilizó y se redujo levemente en 2010-2012. ${ }^{45}$

Por su parte, el aumento porcentual de mujeres condenadas refleja cambios también recogidos por las estadísticas del INE, que muestran cómo las mujeres representan un porcentaje creciente del conjunto de las personas condenadas durante el período de tiempo entre las dos muestras. ${ }^{46}$

\subsubsection{Clase de infracción realizada}

El conjunto de las ejecutorias analizadas corresponde a 3.417 infracciones cometidas, de las cuales 3.175 son delitos. Como refleja la Tabla 5, los delitos más numerosos son contra la seguridad vial $(39,3 \%$ del total, n. 1.248) y contra el patrimonio y el orden socioeconómico sin violencia o intimidación $(22,4 \%$, n. 712$)$. Un 9,73\% de los delitos (n. 309) son lesiones; un $6 \%$ (n. 188) delitos contra la administración de justicia, la mayoría quebrantamientos de condena, un 4,3\% delitos contra la propiedad con violencia o intimidación; un 4,22\% delitos contra el orden público (n. 134); 3,15\% delitos contra la libertad (100), la mayoría amenazas

44 Esta decisión se toma porque ello es lo estadísticamente más probable, dadas las características sociodemográficas de la muestra.

${ }^{45}$ MAHÍA, Ramón (2016): “Evolución de la inmigración en España y mercado de trabajo”, en Anuario CIDOB de la $\quad$ Inmigración, $\quad$ p. $111 . \quad$ Disponible en: https://www.raco.cat/index.php/AnuarioCIDOBInmigracion/article/view/10.24241AnuarioCIDOBInmi.2016. 106 [visitado el 22/02/2020].

${ }^{46}$ Así, por ejemplo, de acuerdo con la estadística de condenados del INE, las mujeres representaron en 2001 un $6,9 \%$ de las personas condenadas, en 2007 un 8,56\% de las mismas, en 2011 un 10,2\% y en 2013 un $11,45 \%$. Estos porcentajes han aumentado desde 2015 (14,35\%), y especialmente desde 2016 (19,24\%), representando las mujeres, según el dato más reciente, un $20,73 \%$ de las personas condenadas en 2018. Las variaciones en las cifras de población femenina en España recogidas por el INE no permiten explicar el incremento en las condenas. De acuerdo con los conocimientos criminológicos sobre delincuencia femenina, las mujeres suponían un mayor porcentaje de las personas condenadas por faltas, en particular contra la propiedad, que por delitos; la supresión de las faltas y la conversión de algunas de ellas en delitos leves que, de este modo, pasan a ingresar la estadística oficial sobre condenados, supondría así un aumento del porcentaje de mujeres condenadas por delito. Por lo tanto, el aumento de mujeres en la estadística de condenados estaría reflejando, por lo menos en parte y desde 2015 y sobre todo 2016, la transformación de algunas faltas, feminizadas en su ejecución, en delitos. Quedaría pendiente de explicar por la investigación criminológica el aumento anterior a 2015. Sobre la delincuencia femenina en España y su castigo ver PEDROSA (2018), passim. 
y coacciones en el ámbito de la pareja. Con una presencia inferior al 3\% de la muestra se encuentran los delitos contra la salud pública, delitos de falsedad; contra los derechos y deberes familiares.

Tabla 5: Infracciones castigadas (muestras 1998, 2015-2016) ${ }^{47}$

\begin{tabular}{|c|c|c|c|c|}
\hline & $\begin{array}{l}2015-2016 \\
\mathrm{~N}\end{array}$ & $\begin{array}{l}2015-2016 \\
\%\end{array}$ & $1998 \mathrm{~N}$ & $1998 \%$ \\
\hline Propiedad sin violencia o intimidación & 712 & 22,4 & 714 & 43,2 \\
\hline Seguridad vial & 1248 & 39,3 & 501 & 30,4 \\
\hline Lesiones & 309 & 9,73 & 100 & 6 \\
\hline Contra la administración de justicia & 188 & 6 & 51 & 3,1 \\
\hline $\begin{array}{l}\text { Propiedad con violencia o } \\
\text { intimidación }\end{array}$ & 137 & 4,3 & ND & ND \\
\hline Contra el orden público & 134 & 4,22 & ND & ND \\
\hline Contra la libertad & 100 & 3,15 & ND & ND \\
\hline Tráfico de drogas & 92 & 2,9 & 62 & 3,7 \\
\hline Falsedades & 71 & 2,2 & 42 & 2,5 \\
\hline Impago o abandono de familia & 69 & 2,2 & 11 & 0,7 \\
\hline Otros & 115 & 3,6 & 141 & 8,5 \\
\hline Total delitos & 3175 & 100 & 1622 & 100 \\
\hline Faltas & 242 & & & \\
\hline Total infracciones & 3417 & & & \\
\hline
\end{tabular}

Fuente: Elaboración propia a partir de los datos obtenidos por Cid y Larrauri (2002) y de datos propios.

La comparación de los delitos cometidos en 1998 y en 2015-2016 recogida en la Tabla 5 permite señalar algunas cuestiones. Se observa una reducción del peso de los delitos cometidos contra la propiedad sin violencia o intimidación, en el conjunto de delitos, que pasan del $43,2 \%$ al $22,4 \%$ del total, y el aumento porcentual de los delitos contra la seguridad vial, que pasan del 30,4 al 39,3\%. Ello puede explicarse por las importantes reformas del Código penal en materia de delincuencia contra la seguridad vial operadas especialmente en $2007,{ }^{48}$ que además de modificar la penalidad en esta materia pasa a añadir conductas punibles, como la conducción a velocidad excesiva (art. 379.1 CP) o la conducción sin permiso (art. $384 \mathrm{CP}$ ). Por su parte, el aumento de la importancia relativa de los delitos de

47 Agradecemos a los doctores Elena Larrauri y José Cid el acceso a la base de datos empleada para su investigación. La base de datos de ejecutorias de 1998 no recoge los tipos penales específicos por los que se condena a los penados, sino que los presenta en las categorías reflejadas en la tabla. En nuestra investigación hemos optado por recoger los tipos penales por su numeración en la parte especial del Código penal y por su nomenclatura exacta. Para elaborar la tabla comparativa, sin embargo, hemos unificado los tipos en categorías similares a las empleadas por la investigación de Cid y Larrauri. En el caso de los delitos contra la seguridad vial cabe advertir que la investigación de Cid y Larrauri se refiere a las alcoholemias. Modificaciones legislativas posteriores han incrementado los tipos penales referidos a la seguridad vial.

${ }^{48}$ Ley Orgánica 15/2007, de 30 de noviembre, por la que se modifica la Ley Orgánica 10/1995, de 23 de noviembre, del Código Penal en materia de seguridad vial. Boletín Oficial del Estado núm. 288. Disponible en: https://www.boe.es/buscar/doc.php?id=BOE-A-2007-20636 [visitado el 22/02/2020]. 


\section{Polít. Crim. Vol. 16, No 31 (Junio 2021), Art. 5, pp. 115-145 \\ [http://politcrim.com/wp-content/uploads/2021/04/Vol16N31A5.pdf]}

lesiones, los delitos contra la libertad y los delitos contra la Administración de Justicia (en su mayoría quebrantamientos de órdenes de protección o de penas de alejamiento) pueden explicarse asimismo por otro conjunto importante de reformas relativas al castigo de la violencia doméstica y de la violencia de género ${ }^{49}$. A pesar de estas diferencias, como en 1998 , en 2015-2016 el grueso de la delincuencia castigada por los juzgados de lo penal es no violenta y no especialmente grave, aunque en la muestra más reciente parece haber una mayor diversidad de delitos.

\subsubsection{Historial delictivo}

El Cuadro 1 refleja el historial delictivo de los integrantes de la muestra:

Cuadro 1: Historial delictivo de los integrantes de la muestra (2015-2016)

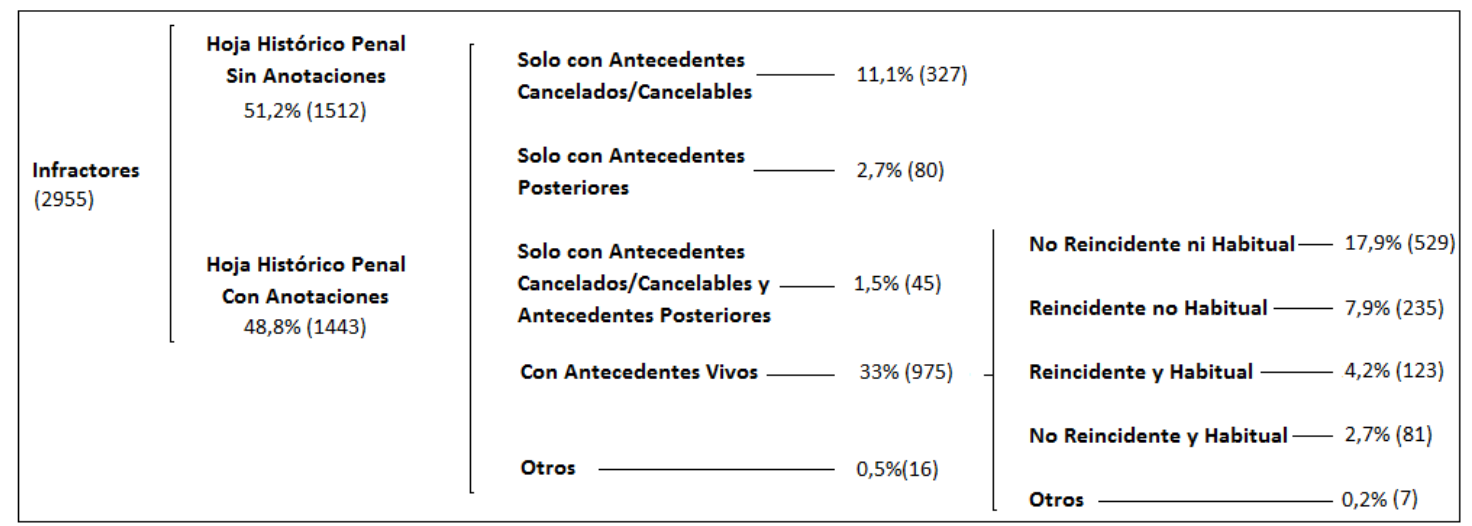

En el conjunto de las muestras, ${ }^{50}$ algo más de la mitad de las personas penadas carecen de antecedentes penales de cualquier tipo, teniendo hojas histórico penales en blanco. Un 33\% de los infractores (n. 975) tiene antecedentes penales vivos, mientras que un $67 \%$ de los infractores carece de ellos (n. 1980). Un 9,5\% de los infractores es reincidente (n. 358) y un $6,9 \%$ es habitual (n. 202). ${ }^{51}$

\footnotetext{
${ }^{49}$ En este sentido cabe mencionar las reformas operadas por la Ley Orgánica 11/2003, de 29 de septiembre, de medidas concretas en materia de seguridad ciudadana, violencia doméstica e integración social de los extranjeros. Boletín Oficial del Estado núm. 234, de 30 de septiembre de 2003. Disponible en: https://www.boe.es/buscar/doc.php?id=BOE-A-2003-18088 [visitado el 22/02/2020]; y la Ley Orgánica 1/2004, de 28 de diciembre, de Medidas de Protección Integral contra la Violencia de Género. Boletín Oficial del Estado núm. 313, de 29 de diciembre de 2004. Disponible en: https://www.boe.es/buscar/doc.php?id=BOEA-2004-21760 [visitado el 22/02/2020].

${ }^{50}$ Se excluyen de este cálculo 4 personas respecto de las cuales no constan o no quedan claros los antecedentes penales, por lo que el n. total en este caso es de 2955.

${ }^{51}$ La terminología es la utilizada en el CP español: antecedentes cancelados o cancelables son aquellos que, por haber transcurrido sin volver a delinquir los plazos señalado en el art. $136 \mathrm{CP}$, han caducado y por tanto no podrían ser tenidos en cuenta a ningún efecto. Antecedentes posteriores son condenas firmes posteriores al delito que se está ejecutando. Por el contrario, antecedentes vivos se refiere a la existencia de una condena firme por hechos anteriores al delito que se está ejecutando y que, al no haber transcurrido los plazos del art. $136 \mathrm{CP}$ no han caducado. Dentro de los que presentan antecedentes vivos, a su vez, cabe distinguir aquellos que serían reincidentes (esto es, que los que, según el art. 22.8 ${ }^{\mathrm{a}}$, tienen una condena firme anterior por un delito comprendido en el mismo título del Código Penal y de la misma naturaleza), y los que tienen la consideración
} 
BLAY GIL, Ester; VARONA GÓMEZ, Daniel: “El castigo en la España del siglo XXI. Cartografiando el iceberg de la penalidad".

Tabla 6: Historial delictivo de los integrantes de las muestras (1998-2015/2016)

\begin{tabular}{|l|l|l|l|l|}
\hline & 1998 & $1998 \%$ & $2015 / 2016$ & $2015 / 2016 \%$ \\
\hline $\begin{array}{l}\text { Sin anotaciones en } \\
\text { hoja histórico-penal }\end{array}$ & 789 & $58 \%$ & 1512 & $51,2 \%$ \\
\hline $\begin{array}{l}\text { Solo antecedentes } \\
\text { cancelables }\end{array}$ & 108 & $8 \%$ & 327 & $11,1 \%$ \\
\hline $\begin{array}{l}\text { Solo } \\
\text { antecedentes con } \\
\text { posteriores }\end{array}$ & 46 & $3,5 \%$ & 80 & $2,7 \%$ \\
\hline $\begin{array}{l}\text { Con antecedentes } \\
\text { cancelables y } \\
\text { posteriores }\end{array}$ & 14 & $1 \%$ & 45 & $1,5 \%$ \\
\hline $\begin{array}{l}\text { Antecedentes vivos } \\
\text { (aavv) }\end{array}$ & 408 & $29,5 \%$ & 975 & $33 \%$ \\
\hline $\begin{array}{l}\text { AAVV no } \\
\text { reincidentes }\end{array}$ & 131 & $9,5 \%$ & 605 & $7,9 \%$ \\
\hline $\begin{array}{l}\text { AAVV reincidentes } \\
\text { no habituales }\end{array}$ & 141 & $10 \%$ & 235 & $6,9 \%$ \\
\hline AAVV habituales & 136 & $10 \%$ & 204 & $12002)$. \\
\hline
\end{tabular}

Fuente: elaboración propia a partir de datos primarios y de datos de Cid y Larrauri (2002).

De la comparación de la muestra correspondiente a 2015/2016 con la del estudio de Cid y Larrauri $^{52}$ cabe destacar la disminución del porcentaje de personas sin ningún historial delictivo, que en 1998 constituían el 58\% (n. 789) de la muestra y actualmente representan un $51,2 \%$ de la misma. Este dato parece reflejar que entran menos personas "nuevas" en el sistema de justicia penal, y que tienden a volver a ser procesadas y condenadas en mayor medida personas que ya lo fueron con anterioridad. ${ }^{53}$

Por otra parte, cabría destacar, aunque en menor medida, el aumento porcentual de las personas con antecedentes cancelables y vivos y la disminución porcentual de las personas consideradas habituales. Esto podría estar reflejando que los usuarios del sistema penal, aunque reincidentes en su mayoría, tienen carreras delictivas menos largas y complejas que en el pasado.

\subsubsection{Situación del penado en el momento de la apertura de la ejecutoria}

Del conjunto de penados, únicamente un 7,4\% estaba en prisión en el momento de apertura de la ejecutoria, en la mayor parte de los casos $(5,8 \%)$ por una causa distinta a la correspondiente al objeto de la ejecutoria analizada. El recurso a la prisión provisional respecto de la muestra analizada es, pues, muy minoritario (un 1,6\% de las personas de la muestra se encuentran en prisión provisional).

de "reo habitual" (art. 94 CP: "los que hubieren cometido tres o más delitos de los comprendidos en un mismo capítulo, en un plano no superior a cinco años, y hayan sido condenados por ello").

${ }_{53}^{52}$ CID y LARRAURI (2002), passim.

${ }^{53}$ Esta disminución de las personas sin antecedentes penales es más significativa si se tiene en cuenta que un $55,73 \%$ (n. 671) de la muestra en Girona carecía de antecedentes penales mientras que en Barcelona únicamente tenían hojas histórico-penales en blanco un $48 \%$ (n. 841). Una posible interpretación de esta diferencia puede estar relacionada con el peso que los delitos contra la seguridad vial tienen en la muestra de Girona (mientras que la delincuencia en Barcelona es más variada): de la mano de la seguridad vial estarían entrando en el sistema de justicia penal más personas "normalizadas", que tienden a carecer de antecedentes penales. 


\section{Polít. Crim. Vol. 16, № 31 (Junio 2021), Art. 5, pp. 115-145 \\ [http://politcrim.com/wp-content/uploads/2021/04/Vol16N31A5.pdf]}

Tabla 7: Situación personal de los integrantes de la muestra en el momento de apertura de la ejecutoria (2015-2016)

\begin{tabular}{|c|c|c|}
\hline & N. personas & $\%$ personas \\
\hline Personas en libertad & 2741 & $92,6 \%$ \\
\hline Total de personas en prisión & 218 & $7,4 \%$ \\
\hline $\begin{array}{l}\text { Personas en prisión } \\
\text { provisional por esta causa }\end{array}$ & 47 & $1,6 \%$ \\
\hline $\begin{array}{l}\text { Personas en prisión por otra } \\
\text { causa distinta }\end{array}$ & 171 & $5,8 \%$ \\
\hline Total de la muestra & 2959 & $100 \%$ \\
\hline
\end{tabular}

En términos globales, el porcentaje de personas privadas de libertad en el momento de apertura de la ejecutoria ha disminuido considerablemente respecto de la muestra de 1998, en que un $19,5 \%$ de las personas se encontraban privadas de libertad, lo que se corresponde con los datos generales sobre el descenso del recurso a la prisión preventiva. ${ }^{54}$

\subsubsection{Clase de juicio (con o sin conformidad)}

En nuestra investigación, como sucede en términos generales, ${ }^{55}$ la forma mayoritaria de llegar a una sentencia condenatoria es mediante la conformidad entre la acusación y la defensa: en conjunto, un $70,7 \%$ de las sentencias de la muestra lo son por conformidad (n. 2.092). Del conjunto de sentencias de conformidad, un 42,3\% (n. 885) lo son en el Juzgado de Guardia, por lo que se trata de "conformidades premiadas" (ver nota al pie 28), y un 57,7\% lo son en los Juzgados de lo Penal. ${ }^{56}$

En la muestra de 1998 las sentencias por conformidad representaron un 69,8\% del total, por lo que la cifra global se mantiene estable. En ese trabajo se hipotetizaba que la conformidad estaría asociada a una mayor aplicación de las alternativas, pues la persona tendería a conformarse con una propuesta penológica que evitase la ejecución de una pena privativa de libertad. ${ }^{57}$ Ello viene confirmado por el análisis realizado con datos de nuestra muestra, que evidencian la fuerte relación entre la conformidad y la concesión de la suspensión de la pena..$^{58}$

De acuerdo con los datos anteriores, pues, el perfil de la persona penada en nuestra muestra es el de un varón español, sin antecedentes penales, condenado en una sentencia de

\footnotetext{
${ }^{54}$ Ver por ejemplo MORILLAS CUEVA (2016), pp. 30-31. Ver una posible explicación sobre el relevante descenso de la prisión preventiva en España en CID (2020), p. 13.

55 Ver por todos The Disappearing Trial. Towards a rights-bases approach to trial waiver systems (https://www.fairtrials.org/publication/disappearing-trial-report). Y LANGER (2004), pp. 1-64.

${ }^{56}$ En este extremo las diferencias entre los dos partidos judiciales son considerables: en Girona un 76,03\% de las sentencias lo son por conformidad (con un 38,8\% en la Guardia y un 37,14\% en los juzgados de lo penal); en Barcelona, en cambio, un 66,2\% de las sentencias lo son por conformidad (22,7\% en la Guardia y $43,5 \%$ en el juzgado de lo Penal). Nuestra hipótesis es que ello puede estar relacionado con las diferencias en la tipología delictiva en ambos partidos, con una mayor proporción de delitos contra la seguridad vial, que tienden en mayor medida a terminar en una conformidad en la Guardia, en Girona, frente a una tipología delictiva más variada en Barcelona.

${ }^{57}$ CID y LARRAURI (2002), p. 37.

58 VARONA GÓMEZ (2019b), passim.
} 
conformidad por la comisión de un delito no violento, en libertad en el momento de la ejecutoria. $^{59}$

\subsection{La discrecionalidad judicial en las penas impuestas y ejecutadas}

\subsubsection{La discrecionalidad judicial en la imposición de las penas}

En este subapartado se recoge la descripción de las penas impuestas por los jueces en sentencia. No analizamos así todavía las decisiones judiciales sobre la suspensión o sustitución de la pena. En consecuencia, cualquier interpretación debe tener en cuenta que estos datos no están reflejando las penas efectivamente ejecutadas.

El análisis de las muestras obtenidas en los partidos judiciales de Barcelona y Girona refleja que la pena más impuesta por los jueces es la multa $(46,31 \%$ de las penas impuestas, n. 1.682), seguida por la prisión (que representa el 44,2\% de las penas impuestas, n. 1.605). Por su parte, los trabajos en beneficio de la comunidad constituyen prácticamente el $8,5 \%$ de las penas impuestas (n. 308), mientras que la localización permanente tiene un uso muy escaso.

La comparación entre las penas impuestas en 2015-2016 y en 1998 comporta por lo menos tres dificultades. En primer lugar, ha cambiado la realidad delictiva del país, pudiéndose hablar en términos generales de un descenso de la delincuencia en España de acuerdo con una diversidad de indicadores, que la sitúa entre los países con tasas más bajas de delitos en la Unión Europea. ${ }^{60}$ En segundo lugar, el Código Penal, como se ha expresado en la introducción a este trabajo, ha sufrido un gran número de modificaciones por lo que se refiere a las conductas punibles y las penas a imponer; ello por sí mismo ha supuesto un aumento de la intervención penal en dos áreas de gran relevancia en la actualidad (la regulación de la delincuencia contra la seguridad vial y de la violencia doméstica y de género).

Un tercer obstáculo lo constituye el hecho que la competencia de los Juzgados de lo Penal es en la actualidad distinta que en el momento de recogida de la muestra de 1998, correspondiente a sentencias dictadas en los meses de abril y mayo. En ese momento, los Juzgados de lo Penal eran competentes para enjuiciar las causas por delitos castigados con penas menos graves (entonces penas de prisión de 3 meses a 3 años, de acuerdo con la redacción original del art. 33 en el Código penal de 1995). Desde noviembre 1998 los

\footnotetext{
${ }^{59}$ Podríamos añadir, con nuestros datos, que como en 1998 estos penados han sido defendidos por abogados mayoritariamente de oficio (en un 84,6\%). Por otra parte, en sus expedientes tiende a no constar información individualizada más allá de la hoja histórico penal: únicamente en un 2,2\% de los expedientes se dispone de un informe criminológico sobre las circunstancias del penado, solicitado por el juez.

${ }^{60}$ Ver para la evolución hasta 2008, GARCÍA ESPAÑA et al. (2010), passim. Para fechas posteriores, ver estadísticas oficiales sobre hechos conocidos y/o tasas de criminalidad en los Anuarios Estadísticos del Ministerio del Interior de los años 2016, 2012, 2007, por ejemplo. Disponibles en: http://www.interior.gob.es/web/archivos-y-documentacion/documentacion-y-publicaciones/anuarios-yestadisticas [visitado el 22/02/2020]. Para un análisis agregado de datos policiales en el contexto europeo en el periodo 2008-2017 ver las estadísticas recogidas por Eurostat. Disponible en: https://ec.europa.eu/eurostat/web/crime/data/database [visitado el 22/02/2020].
} 


\section{Polít. Crim. Vol. 16, No 31 (Junio 2021), Art. 5, pp. 115-145 [http://politcrim.com/wp-content/uploads/2021/04/Vol16N31A5.pdf]}

Juzgados de lo Penal son competentes para conocer de las causas por delitos castigados con pena privativa de libertad no superior a los 5 años. ${ }^{61}$

Con todas estas limitaciones y salvedades, cualquier afirmación sobre la evolución de las penas impuestas debe ser necesariamente tentativa. Sin embargo, y a la espera de análisis pormenorizados sobre la respuesta judicial a tipos delictivos comparables, la Tabla 8 presenta conjuntamente los datos correspondientes a las penas impuestas en las dos muestras.

Tabla 8: Las penas principales impuestas (1998, 2015-2016)

\begin{tabular}{|l|l|l|l|l|}
\hline Tipo de pena & $1998 \mathrm{n}$. & $1998 \%$ & $2015-2016 \mathrm{n}$. & $2015-2016 \%$ \\
\hline Prisión & 574 & 40,5 & 1605 & 44,2 \\
\hline Multa & 809 & 57 & 1682 & 46,31 \\
\hline TBC & 0 & 0 & 308 & 8,48 \\
\hline AFS/AD/LP & 35 & 2,5 & 37 & 1,01 \\
\hline Total & 1418 & 100 & 3632 & 100 \\
\hline
\end{tabular}

Fuente: elaboración propia a partir de datos primarios y de datos de Cid y Larrauri (2002).

La comparación entre las penas impuestas en 1998 y en 2015/2016 revela un aumento de la aplicación de la pena de prisión en casi un $4 \%$. Este aumento, en principio y a falta según decimos de análisis más sofisticados, no parecería indicativo de un aumento de punitividad judicial debido a que la delincuencia procesada en 2015-2016 es más grave (delitos de hasta cinco años de prisión) que la gestionada en 1998 (delitos de hasta tres años de prisión). Adicionalmente, puede apreciarse una considerable disminución en el porcentaje de aplicación de la multa (de un 57\% a un 46,3\% del total de penas impuestas), así como la consolidación del TBC como opción punitiva en nuestro catálogo de penas. Aunque introducida en el CP de 1995, esta pena no tuvo una aplicación significativa hasta prácticamente $2004 .{ }^{62}$

Por su parte, si en la muestra de 1998 la aplicación de los arrestos de fin de semana y arrestos domiciliarios ${ }^{63}$ era anecdótica, la aplicación de la actual localización permanente lo es en mayor medida. No parece que la configuración legal o las formas de ejecución de esta pena privativa de libertad sea especialmente creíble para los jueces, que recurren a la misma en

\footnotetext{
${ }^{61}$ Modificación operada en el art. 14.3 de la Ley de Enjuiciamiento Criminal mediante Ley 36/1998, de 10 de noviembre, de modificación del artículo 14, apartados primero y tercero, de la Ley de Enjuiciamiento Criminal, que entró en vigor el 12 de noviembre de 1998. Disposición publicada en el Boletín Oficial del Estado núm. 270, de 11 de noviembre de 1998. Disponible en: https://www.boe.es/buscar/doc.php?id=BOE-A-1998-25933 [visitado el 22/02/2020].

${ }^{62}$ BLAY (2010), pp. 62-81.

${ }^{63}$ Los arrestos domiciliarios se recogían en el Código penal de 1973 y no integraron el catálogo de penas del Código penal de 1995. Por su parte, el arresto de fin de semana fue eliminado del catálogo de penas por el legislador mediante la Ley Orgánica 15/2003, de 25 de noviembre, por la que se modifica la Ley Orgánica 10/1995, de 23 de noviembre, del Código Penal. Como se plasma en la Exposición de Motivos de la propia, ley, la "aplicación práctica" del arresto "no ha sido satisfactoria, sustituyéndose, según los casos, por la pena de prisión de corta duración - de tres meses en adelante en los delitos-, por la pena de trabajo en beneficio de la comunidad o por la pena de localización permanente", introducida por esta misma Ley (Boletín Oficial del Estado núm. 283, de 26 de noviembre de 2003). Disponible en: https://www.boe.es/buscar/doc.php?id=BOEA-2003-21538 [visitado el 22/02/2020].
} 


\section{BLAY GIL, Ester; VARONA GÓMEZ, Daniel: “El castigo en la España del siglo XXI. Cartografiando el iceberg de la penalidad".}

pocas ocasiones incluso teniendo en cuenta lo limitado de su ámbito de aplicación. ${ }^{64}$ En su conjunto, este primer momento de aplicación judicial de las penas estaría revelando un panorama en que la multa y la prisión serían las respuestas a la gran mayoría de los delitos, con un recurso minoritario al TBC. Ello, sin embargo, insistimos, no refleja las penas definitivamente impuestas por los jueces.

5.2.2. La discrecionalidad judicial en el momento de la ejecución de la pena: la aplicación de la suspensión y la sustitución de las penas

En este subapartado se muestran en primer lugar los resultados de la toma de decisiones judiciales alrededor de la suspensión de las penas de prisión y en segundo lugar se ofrece una descripción de las penas definitivamente impuestas, teniendo en cuenta esas decisiones.

Cabe resaltar, como sucedía con la muestra de 1998 y como mostraban estudios sobre la aplicación de las penas en ámbitos específicos, ${ }^{65}$ que la mayor parte de las penas de prisión impuestas no se ejecutan, sino que se suspenden o sustituyen. Así, de acuerdo con los datos reflejados en el Cuadro 2, en nuestro estudio se suspendieron un 62,55\% de las penas de prisión impuestas y se sustituyeron un $13,08 \%$ de las mismas. ${ }^{66}$ Los datos muestran que a pesar de que la pena de prisión se impone bastante, se estarían ejecutando de forma efectiva únicamente un 20,6\% de las penas de prisión impuestas, cumpliéndose el resto de condenas a prisión de forma alternativa. Estos datos confirman la historia de éxito de la suspensión en España. ${ }^{67}$

Más del $80 \%$ de las suspensiones concedidas son ordinarias, es decir, suspensiones durante las cuales la única regla que debe cumplir la persona penada es no volver a delinquir. Las suspensiones con reglas de conducta, las suspensiones especiales para drogodependientes y las suspensiones extraordinarias son en la práctica bastante excepcionales.

\footnotetext{
${ }^{64}$ TORRES ROSELL (2012), passim. El ámbito de aplicación de esta pena se ha visto reducido por la reforma operada en el Código penal por la Ley Orgánica 1/2015, de 30 de marzo, por la que se modifica la Ley Orgánica 10/1995, de 23 de noviembre, del Código Penal, Boletín Oficial del Estado núm. 77, de 31 de marzo de 2015. Disponible en: https://www.boe.es/diario_boe/txt.php?id=BOE-A-2015-3439 [visitado el 22/02/2020].

${ }^{65}$ ANTÓN GARCÍA y LARRAURI PIJOAN (2009), passim.

${ }^{66}$ Cabe aclarar que, tal y como expusimos en supra not. 17, la reforma del CP llevada a cabo en 2015 subsumió la institución de la sustitución de la pena de prisión (por multa o TBC) prevista en el art. 88, en la actual suspensión extraordinaria o con pena añadida (arts. 80.3 y 84). Esta reforma también explica que en el cuadro aparezca por dos veces la suspensión especial para drogodependientes (al venir regulada en preceptos diferentes antes y después de la reforma).

${ }^{67}$ VARONA GÓMEZ (2019a), pp. 251-252 y VARONA GÓMEZ (2019b), passim.
} 


\section{Polít. Crim. Vol. 16, No 31 (Junio 2021), Art. 5, pp. 115-145 \\ [http://politcrim.com/wp-content/uploads/2021/04/Vol16N31A5.pdf]}

Cuadro 2: La ejecución de las penas de prisión $(2015 / 2016)^{68}$

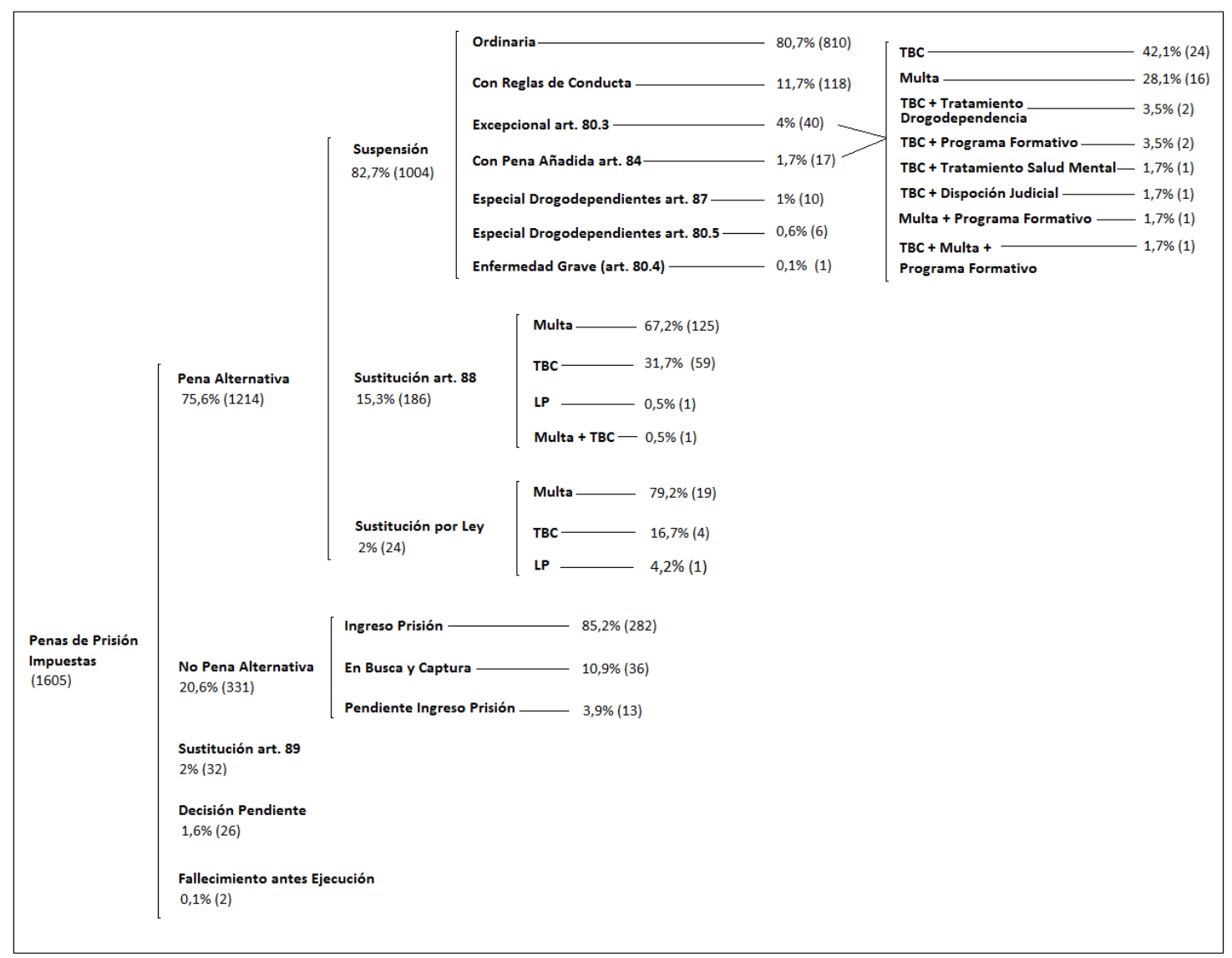

Como se desprende del cuadro anterior, la concesión de formas alternativas de cumplimiento de la pena de prisión, la suspensión, y en menor medida de la sustitución, evita la mayor parte del cumplimiento de las penas de prisión impuestas en forma de encierro penitenciario. ${ }^{69}$

Este hallazgo de nuestra investigación viene corroborado adicionalmente por los datos a nivel nacional relativos a las entradas en prisión y el número de condenas a prisión en España. El número de entradas a prisión por año no se recoge en estadísticas oficiales, pero puede hallarse en la investigación de Cid Moliné. ${ }^{70} \mathrm{Si}$ cruzamos el dato sobre entradas en prisión de los años 2015 y 2016 (que son los que corresponden con nuestra investigación) contenidos en el trabajo de Cid Moliné, con los datos sobre población española en tales años (disponible

\footnotetext{
${ }^{68}$ Como en otros indicadores, en este cuadro se presentan los datos agregados para las muestras recogidas en Barcelona y en Girona. Cabe mencionar que el análisis separado de las muestras revela algunas diferencias entre ambos partidos, en particular un mayor recurso a las alternativas a las penas de prisión en los Juzgados de Girona. En un futuro trabajo se describirán y explicarán estas diferencias.

${ }^{69}$ La sustitución del art. 89 CPE se refiere a la sustitución de la pena de prisión por la expulsión del territorio en caso de extranjeros. Y la "sustitución por ley" se refiere al supuesto establecido en el art. 71.2 CPE en el que por aplicación de atenuantes u otras circunstancias la pena sea inferior a tres meses de prisión, en cuyo caso es imperativo sustituirla por multa, TBC o LP.
}

${ }^{70}$ véase CID (2020), p. 3. 
en el $\mathrm{INE}^{71}$ ) y finalmente con el número de condenas a pena de prisión de los mismos años (que puede consultarse en las estadísticas de condenados del INE), obtenemos finalmente que en el año 2015, del total de penas de prisión impuestas, un $23 \%$ finalizaron con una entrada efectiva en prisión, y en el año 2016 se repite exactamente el mismo porcentaje. Como puede observarse ello es muy cercano al dato hallado en nuestra investigación y reflejado en el cuadro anterior que muestra cómo de las penas de prisión impuestas, aproximadamente un $20 \%$ no se beneficiaron de pena alternativa alguna y por lo tanto implicaron un ingreso efectivo en prisión.

Volviendo al conjunto de opciones penológicas, al tener en cuenta las decisiones judiciales relacionadas con la concesión de la suspensión y la sustitución, los datos evidencian que la multa es la opción penológica más empleada por los jueces (46,31\% de las ocasiones), seguida de la suspensión de la pena $(27,65 \%$ de las ocasiones). A mucha distancia se encuentran las penas de prisión ejecutadas mediante un encierro penitenciario $(9,11 \%$ de las condenas definitivas), prácticamente al mismo nivel que las penas de TBC $(8,48 \%)$.

Tabla 9: Las penas definitivas impuestas (1998 y 2015-2016)

\begin{tabular}{|l|l|l|l|l|}
\hline Tipo de pena & $1998 \mathrm{n}$. & $1998 \%$ & $2015-2016 \mathrm{n}$. & $2015-2016 \%$ \\
\hline Prisión & 241 & 17 & $331 * *$ & 9,11 \\
\hline TBC & 0 & 0 & 308 & 8,48 \\
\hline Multa & 809 & 57 & 1682 & 46,31 \\
\hline AFS/AD/LP & 35 & 2,4 & 37 & 1,01 \\
\hline Suspensión & 333 & 23,5 & 1004 & 27,65 \\
\hline Sustitución* & & & 210 & 5,78 \\
\hline Sustitución por expulsión & 0 & & 32 & 0,88 \\
\hline $\begin{array}{l}\text { Pendiente } \\
\text { decisión/fallecimiento }\end{array}$ & 0 & 28 & 0,77 \\
\hline Total & 1418 & $100 \%$ & 3632 & $100 \%$ \\
\hline
\end{tabular}

*Incluye para 2015-2016 la sustitución por ley (art. 71.2 CP): n. 24

**Incluye personas en busca y captura y pendientes de ingreso (n. 49); no incluye los casos de fallecimiento antes de la ejecución o de decisión pendiente (n. 28).

Fuente: elaboración propia a partir de datos primarios y de datos de Cid y Larrauri (2002).

Los datos recogidos en la tabla anterior señalan una reducción del porcentaje de penas de prisión como penas definitivas en relación con la muestra de 1998: las penas de prisión ejecutadas como tal suponían en 1998 un 17\% del total de penas impuestas, mientras que en 2015-2016 representan únicamente un 9,11\% del total. Ello parece correlacionar con el correspondiente aumento de las formas sustitutivas de cumplimiento de la prisión: la suspensión de la pena ha pasado de un $23,5 \%$ a un $27,6 \%$ del conjunto de penas impuestas, y la sustitución, que en 1998 tenía una aplicación negligible, supone casi un $6 \%$ del conjunto de respuestas penales en la muestra de $2015-2016 .^{72}$

\footnotetext{
${ }^{71}$ El trabajo del profesor Cid proporciona la ratio de entradas por 100.000 habitantes, por lo que para hallar el número de entradas en prisión por año es necesario hallar el dato de la población española y realizar una regla de tres.

72 Según decíamos, la posibilidad de sustituir penas de prisión por multa o TBC fue eliminada por la Ley Orgánica 1/2015, que deroga el artículo 88 del Código penal; esta misma reforma contempla la posibilidad de imponer como regla de conducta en casos de suspensión la multa o el TBC (Ley Orgánica 1/2015, de 30 de marzo, por la que se modifica la Ley Orgánica 10/1995, de 23 de noviembre, del Código Penal. Boletín Oficial
} 


\section{Polít. Crim. Vol. 16, No 31 (Junio 2021), Art. 5, pp. 115-145 [http://politcrim.com/wp-content/uploads/2021/04/Vol16N31A5.pdf]}

Estos datos estarían poniendo en evidencia que los jueces no están privilegiando la prisión como respuesta a la delincuencia, sino las alternativas a la misma en forma de suspensiones y multas y, en menor medida, penas de TBC.

\section{Discusión y conclusiones}

El objetivo general de este trabajo es presentar una cartografía actual del sistema punitivo español, buscando contribuir a la discusión criminológica en España, que en los últimos años se ha centrado, como hemos explicitado, en las reformas legislativas y en el crecimiento de la población penitenciaria. Adicionalmente, se ha buscado comparar los datos obtenidos en nuestra investigación con los correspondientes a la investigación liderada por los profesores Cid y Larrauri, ${ }^{73}$ tratando de trazar así cuál ha sido la evolución del sistema punitivo español. Para conseguir estos objetivos se ha recurrido a datos primarios obtenidos de muestras representativas del conjunto de ejecutorias de los Juzgados de lo penal de Barcelona y Girona para los años 2015 y 2016.

Los datos así obtenidos reflejan que la pena a la que más recurren los Juzgados de lo penal es la multa, que constituye el $46 \%$ del conjunto de penas impuestas. Paradójicamente, se trata de una pena a la que, salvo honrosas excepciones ${ }^{74}$ se ha prestado escasa atención desde la investigación criminológica y penológica, si se la compara con la recibida por la prisión o por los trabajos en beneficio de la comunidad. En segundo lugar, la prisión se impone como pena en un $44 \%$ de los casos. Si tenemos en cuenta la decisión judicial de la suspensión y la sustitución de las penas de prisión, sin embargo, veremos que la prisión constituye únicamente un 9,11\% del conjunto de penas definitivas impuestas. Ello es así porque la mayor parte de las penas de prisión se cumplen mediante formas de ejecución alternativas, entre las que resulta mayoritaria la suspensión ordinaria. Esta opción representa el 27,65\% de las penas definitivas, y la sustitución de las penas de prisión el 5,78\% de las mismas. Estos datos estarían confirmando la historia de éxito de la suspensión en nuestro país. ${ }^{75}$ Finalmente, cabe destacar que el TBC representa un $8,48 \%$ del total de penas impuestas. Todo ello ratifica que, según decíamos, el mapa de la penalidad española es mucho más complejo que el que revelan las estadísticas oficiales, y que efectivamente, por fortuna, la prisión sigue siendo la punta del iceberg.

Como hemos mencionado, un objetivo adicional de nuestro trabajo ha sido intentar trazar la evolución del sistema penal español comparando los datos obtenidos en nuestra investigación con los datos de la, hasta donde alcanza nuestro conocimiento, única investigación comparable en España, dirigida por Cid y Larrauri, ${ }^{76}$ correspondientes a sentencias

del Estado núm. 77, de 31 de marzo de 2015. Disponible en: https://www.boe.es/diario boe/txt.php?id=BOEA-2015-3439 [visitado el 22/02/2020]).

${ }^{73}$ CID y LARRAURI (2002), passim.

${ }^{74}$ Entre la escasa literatura penológica en España sobre las multas destacan las monografías de ROLDÁN BARBERO (1982), passim; FARALDO CABANA (2017), passim. Hay pocos estudios empíricos sobre la multa, pero cabe destacar el trabajo de GÓMEZ MARTÍN et al. (2016), passim.

${ }^{75}$ VARONA GÓMEZ (2019b), passim.

${ }^{76}$ CID y LARRAURI (2002), passim. 
condenatorias de 1998. Ya se ha explicado que diversas modificaciones legislativas, sustantivas y procesales, y de la realidad social y delictiva en España impiden llegar a conclusiones comparando únicamente datos generales sobre penalidad. Sin embargo, una lectura en paralelo de los resultados de ambas investigaciones permite realizar diversas observaciones tentativas.

Así, en primer lugar, parece que el recurso a la prisión como pena definitiva ha descendido de forma considerable en términos relativos, pues la prisión pasa de representar el 17\% de las penas definitivas impuestas en 1998 al 9,11\% de las mismas en 2015-2016. Ello sería aún más llamativo si tenemos en cuenta la aludida ampliación de la competencia de los juzgados de lo penal, que ahora procesan delitos más graves que en 1998. Este dato puede resultar un tanto sorprendente, especialmente en el contexto del consenso actual acerca del creciente endurecimiento del sistema penal. Frente a lo que podrían llevar a pensar las investigaciones sobre las modificaciones legislativas de los últimos años y los datos sobre el aumento de las tasas de encarcelamiento, si se toman las penas en su conjunto, el peso relativo de la prisión ha disminuido con el tiempo. ${ }^{77}$

La disminución (relativa) de la prisión como pena definitiva está directamente relacionada con el recurso a las formas sustitutivas y suspensivas de cumplimiento de la prisión, cuya aplicación judicial, como hemos visto, ha aumentado. Como se ha sugerido en otros trabajos $^{78}$, la aplicación masiva de la suspensión ordinaria (la "historia de éxito" de la suspensión), está relacionada no tanto con un ánimo consciente y normativo por parte de los operadores jurídicos de evitar el encarcelamiento y aplicar alternativas al mismo sino con razones instrumentales relacionadas con la necesidad de subsistencia del propio sistema penal. La suspensión ordinaria es una opción penológica que (1) facilita enormemente la conformidad del penado; y (2) requiere de escasos recursos para su ejecución: ${ }^{79}$ solo comporta la comunicación a la persona del auto de suspensión, a la que sigue el archivo provisional del caso durante los dos a cinco años que puede durar el plazo de suspensión, después de los cuales se solicita la hoja histórico-penal del penado para verificar si ha sido condenado por algún delito cometido en plazo de suspensión. En el contexto de un sistema penal caracterizado por una enorme expansión y una escasez de recursos, la suspensión es una opción penológica no solo atractiva, sino necesaria.

\footnotetext{
${ }^{77}$ En la muestra correspondiente a sentencias de 1998 las penas de prisión impuestas tenían una media de 8,72 meses de duración, mientras que en las muestras de 2015-2016 la duración media de las penas de prisión es de 9,34 meses, y de 9,56 meses si tenemos en cuenta, como en 1998, únicamente la condena por el delito más grave. La duración de las penas de prisión impuestas, pues, ha aumentado, lo que era esperable teniendo en cuenta que ahora los Juzgados de lo penal son competentes para conocer de delitos más graves, como se ha explicado.

78 VARONA GÓMEZ (2019a), passim; VARONA GÓMEZ (2019b), passim.

${ }^{79}$ Ello vendría reforzado, adicionalmente, por la escasez de información sobre las circunstancias personales y sociales del penado que podría permitir una aplicación individualizada de las reglas de conducta disponibles para el juez. Así, únicamente en un 2,2\% de los casos examinados por los autores hay un informe social o criminológico que permita al juez conocer las circunstancias del penado; en la abrumadora mayoría de casos, la única información individual de la que dispone el juez es la hoja histórico penal.
} 


\section{Polít. Crim. Vol. 16, № 31 (Junio 2021), Art. 5, pp. 115-145 \\ [http://politcrim.com/wp-content/uploads/2021/04/Vol16N31A5.pdf]}

De acuerdo con los datos disponibles, pues, parece que una importante dosis de pragmatismo subyace a la decisión judicial de suspender la mayoría de penas de prisión, y de hacerlo además sin imponer reglas de conducta de trabajosa ejecución.

Otro aspecto relevante de la lectura en paralelo de las penas impuestas en 1998 y en 20152016 es el descenso del peso de la multa en términos relativos, que ha pasado de constituir el 57\% del conjunto de penas definitivas en 1998 al 46,31\% de las mismas en 2015-2016. Por su parte, en este mismo período de tiempo el TBC, que no aparecía como opción penológica relevante en 1998, ha pasado a representar el 8,46\% del conjunto de penas definitivas. Estos datos permiten formular la hipótesis, que deberá ser testada en un futuro estudio, de que en el período de tiempo transcurrido entre la recogida de ambas muestras se han producido los fenómenos identificados de net widening y thinning the mesh. ${ }^{80} \mathrm{La}$ primera expresión (extensión de la red penal) busca reflejar que la introducción de algunas penas alternativas no tiene el efecto de reemplazar a la prisión sino de expandir el control penal a nuevas poblaciones. Los datos muestran que este fenómeno ha tenido lugar en diversas jurisdicciones europeas $^{81}$, de la mano de las llamadas penas comunitarias, de las que el TBC es un ejemplo. ${ }^{82}$ La segunda expresión, thinning the mesh, se refiere a que las penas comunitarias han supuesto un endurecimiento general de las respuestas penales que no implica necesariamente recurrir a la prisión sino dejar de emplear respuestas más leves, como la multa, para imponer penas alternativas de mayor severidad, ${ }^{83}$ como el TBC.

Volviendo a la metáfora del iceberg que da título a este trabajo y poniendo los datos de la investigación presentada en relación con los datos generales sobre incremento de personas condenadas en España, podemos decir que el tamaño del iceberg ha crecido de forma muy considerable: el sistema penal se ha expandido, castigándose ahora a muchas más personas que hace 20 años. Sin embargo, ha seguido configurándose como un iceberg en el que incluso su parte visible (la prisión) se ha hecho más pequeño (en términos porcentuales), y la parte sumergida (el resto de penas) se ha diversificado. Cómo ha sido capaz España de gestionar un crecimiento tan sostenido del sistema sin colapsarse es una muy buena pregunta, que sin embargo debemos dejar para otro trabajo.

\footnotetext{
${ }^{80}$ COHEN (1979), pp. 339-363.

${ }^{81}$ AEBI et al. (2015), p. 590.

${ }^{82} \mathrm{El}$ TBC en España, pues, no habría tenido un impacto descarcelador, a diferencia del evidente efecto descarcelador de la suspensión y sustitución de la pena de prisión.

${ }^{83}$ WASIK y VON HIRSCH (1988), pp. 555-572.
} 
Gráfica 1: Personas condenadas en España (1998-2017)

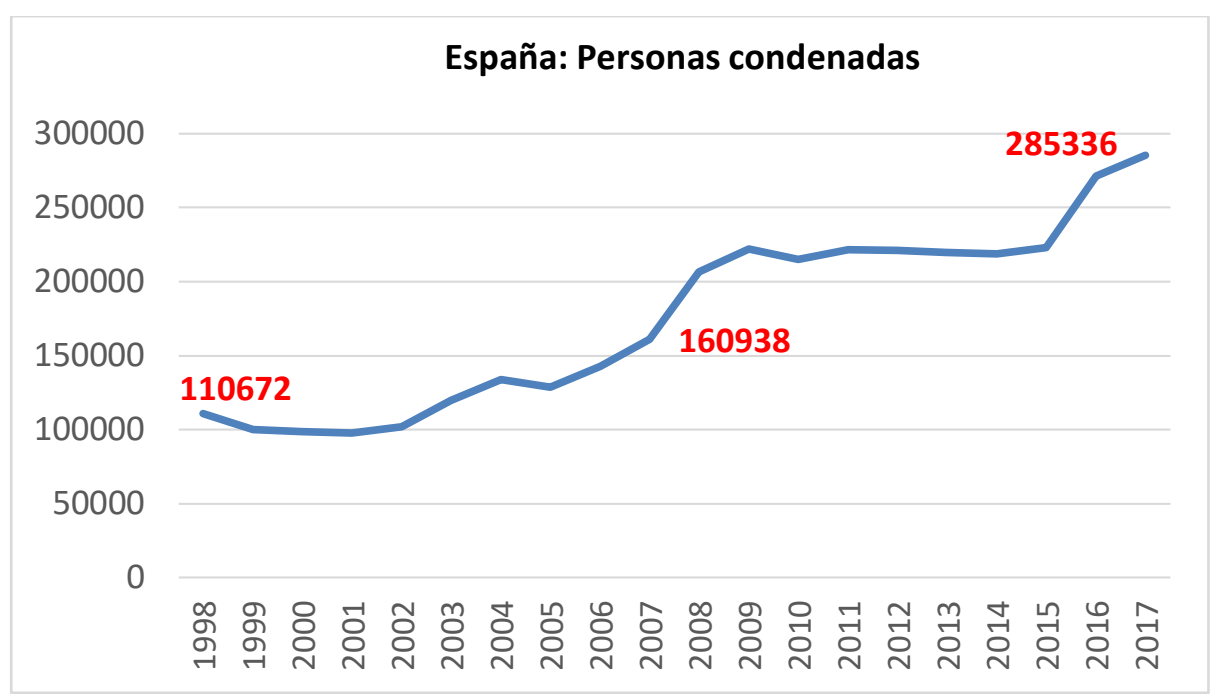

Fuente: $\mathrm{INE}^{84}$

${ }^{84}$ El gran aumento de condenados en 2016 es más nominal que real: se debe a la reforma de 2015 que eliminó las faltas, para pasar a denominarlas "delitos leves", pues el INE solo contabilizaba condenas por delitos (y por tanto ahora también lo que antes eran faltas). 


\section{Polít. Crim. Vol. 16, No 31 (Junio 2021), Art. 5, pp. 115-145 \\ [http://politcrim.com/wp-content/uploads/2021/04/Vol16N31A5.pdf]}

\section{Bibliografía citada}

AEBI, Marcelo; DELGRANDE, Natalia; MARGUET, Yann (2015): "Have community sanctions and measures widened the net of the European criminal justice systems?", en: Punishment and Society (Año 17, Vol. 5), pp. 575-597.

ANTÓN GARCÍA, Lorena; LARRAURI PIJOAN, Elena (2009): "Violencia de género ocasional: un análisis de las penas aplicadas", en: Revista Española de Investigación Criminológica (Núm. 7), pp. 1-26. Disponible en: https://tinyurl.com/yzf36082 [visitado el 26/04/2020].

BLAY, Ester (2010): "'It could be us': Recent Transformations in the Use of Community Service as a Punishment in Spain", en: European Journal of Probation (Año: 2, $\mathrm{N}^{\circ} 1$ ), pp. 62-81.

BLAY, Ester; GONZÁLEZ SÁNCHEZ, Ignacio (2020): Jueces penales. Una introducción al estudio de la profesión (Madrid, Iustel).

BOTTOMS, Anthony (1995): "The philosophy and politics of punishment and sentencing", en: CLARKSON, Chris M.V; MORGAN, Rod (ed.), The Politics of Sentencing Reform (Oxford, Clarendon Press), pp. 17-49.

BRANDARIZ GARCÍA, José Ángel (2014): "La evolución de la penalidad en el contexto de la Gran Recesión: la contracción del sistema penitenciario español", en: Revista de Derecho Penal y Criminología ( $\left.{ }^{\circ} 12\right)$, pp. 309-342.

BRANDARIZ GARCÍA, José Ángel (2018): “An enduring sovereign mode of punishment: Post-dictatorial penal policies in Spain”, en: Punishment and Society (Año 20, $\mathrm{N}^{\circ} 3$ ), pp. 308-328.

CID, José (2017): “¿Un Derecho Penal sin pena de prisión?”, en: CASTIÑEIRA, María Teresa; CORCOY, Mirentxu; QUERALT, Joan Josep; SILVA SÁNCHEZ, Jesús (coord.): Estudios de Derecho Penal. Homenaje al profesor Santiago Mir Puig (Montevideo - Buenos Aires, Editorial B de F), pp. 41-54.

CID, José (2020): "El futuro de la prisión en España”, en: Revista Española de Investigación Criminológica (Año 18, No 1), pp. 1-26. Disponible en: https://tinyurl.com/yg7ajkw4 [visitado el 22/02/2020].

CID, José; LARRAURI, Elena (coord.) (2002): Jueces penales y penas en España (Valencia, Tirant lo Blanch).

COHEN, Stanley (1979): "The punitive city: Notes on the dispersal of social control", en: Contemporary Crises (Año 3), pp. 339 - 363.

DÍEZ RIPOLLÉS, José Luís (2004): "El nuevo modelo penal de la seguridad ciudadana", en: Revista Electrónica de Ciencia Penal y Criminología (Año 6, No 3), pp. 1-34. Disponible en: https://tinyurl.com/yzgu3zbc [visitado el 26/04/2021].

DÍEZ RIPOLLÉS, José Luís (2013a): "Rigorismo y reforma penal. Cuatro legislaciones homogéneas (1996-2011). Parte I", en: Boletín Criminológico (No 142), pp. 1 - 5. Disponible en:[visitado el 22/02/2020].

DÍEZ RIPOLLÉS, José Luís (2013b): "Rigorismo y reforma penal. Cuatro legislaciones homogéneas (1996-2011). Parte II”, en: Boletín Criminológico ( $\mathrm{N}^{\circ}$ 143), pp. 1 - 5. Disponible en: https://tinyurl.com/yk4ktq54 [visitado el 26/04/2021].

DÍEZ RIPOLLÉS, José Luís (2017): "El abuso del sistema penal”, en: Revista Electrónica de Ciencia Penal y Criminología (Año 19, No 1), pp. 1-24. Disponible en: http://criminet.ugr.es/recpc/19/recpc19-01.pdf [visitado el 22/02/2020]. 
FARALDO CABANA, Patricia (2017): Money and the governance of punishment. A genealogy of the penal fine (Londres, Routledge).

GARCÍA ESPAÑA, Elisa; DÍEZ RIPOLLÉS, José Luís; PÉREZ JIMÉNEZ, Fátima; BENÍTEZ JIMÉNEZ, María José y CEREZO DOMÍNGUEZ, Ana Isabel (2010): "Evolución de la delincuencia en España: Análisis longitudinal con encuestas de victimización", en Revista Española de Investigación Criminológica (Año 8, Art. 2), pp. 1-27. Disponible en: https://tinyurl.com/yfw6xp8m [visitado el 26/04/2021].

GARCÍA ESPAÑA, Elisa (2019): "Más inmigración, menos delincuencia", en: Revista Crítica Penal y Poder (Año 18), pp. 194-205.

GARLAND, David (2001): The culture of control. Crime and social order in contemporary society (Oxford, Oxford University Press).

GIL, Alicia; LACRUZ, Juan Manuel; MELENDO, Mariano; NUÑEZ, José (2018): Consecuencias Jurídicas del Delito (Madrid, Dykinson).

GÓMEZ MARTÍN, Víctor; CORCOY BIDASOLO, Mirentxu; CARDENAL MONTRAVETA, Sergi; HORTAL IBARRA, Juan Carlos; VERA SÁNCHEZ, Juan Sebastián; BALAGUER BATALLER, Mireia; VALIENTE IVÁÑEZ, Vicente (2016): La prisión por impago de multa en Cataluña Diagnóstico del problema y propuestas de solución. Catálogo de investigaciones del Centro de Estudios Jurídicos y Formación Especializada de la Generalitat de Catalunya. Disponible en: https://tinyurl.com/ygzdma81 [visitado el 26/04/2021].

GONZÁLEZ SÁNCHEZ, Ignacio (2011): “Aumento de presos y Código penal. Una explicación insuficiente", en: Revista Electrónica de Derecho Penal y Criminología (Año 13, No 4), pp. 1-22. Disponible en: https://tinyurl.com/yztd5gcf [visitado el 26/04/2021].

HAMILTON, Claire (2014): "Reconceptualizing Penality. Towards a Multidimensional Measure of Punitiveness", en: The British Journal of Criminology (Año 54, Vol. 2), pp. $321-343$.

LANGER, Máximo (2004): "From Legal Transplants to Legal Translations: The Globalization of Plea Bargaining and the Americanization Thesis in Criminal Procedure", en: Harvard International Law Journal (Año 48, Vol. 1), pp. 1 -64.

LARRAURI PIJOAN, Elena (2009): "La economía política del castigo", en: Revista Electrónica de Ciencia Penal y Criminología (Año 11, $\mathrm{N}^{\mathrm{o}}$ 6). Disponible en: http://criminet.ugr.es/recpc/11/recpc11-06.pdf [visitado el 22/02/2020].

MAHÍA, Ramón (2016): "Evolución de la inmigración en España y mercado de trabajo", en: Anuario CIDOB de la Inmigración, pp. 106-137. Disponible en: https://tinyurl.com/ygbdalpc [visitado el 26/04/2021].

MATTHEWS, Roger (2005): "The myth of punitiveness", en: Theoretical Criminology (Año 9, vol. 2), pp. 175 -201.

MORILLAS CUEVA, Lorenzo (2016): "Reflexiones sobre la prisión preventiva”, en: Anales de Derecho - Universidad de Murcia ( $\mathrm{N}^{\mathrm{o}} 1$ ), pp. 1-38. Disponible en: https://tinyurl.com/ye4ghjbr [visitado el 26/04/2021].

MORILLAS CUEVA, Lorenzo; BARQUÍN SANZ, Jesús (dir.) (2013): La aplicación de las alternativas a la pena de prisión en España. Defensor del Pueblo, Universidad de Granada. Madrid. Disponible en: https://tinyurl.com/yeumjvz6 [visitado el 26/04/2021]. 
NIETO, Adán; MUÑOZ DE MORALES, Marta; RODRÍGUEZ, Cristina (2017): "Alternativas a la prisión: una evaluación sobre su impacto en la población penitenciaria española”, en: Revista General del Derecho Penal (Vol. 28), pp. 1100.

PEDROSA, Albert (2018): “Discrimina el Código Penal español a las mujeres?”, en: Revista Española de Investigación Criminológica (Año 16, $\mathrm{N}^{\circ}$ 5). Disponible en: https://tinyurl.com/yjxl8dkr [visitado el 22/02/2020].

REDONDO, Santiago; GARRIDO, Vicente (2013): Principios de Criminología (Valencia, Tirant lo Blanch).

ROLDÁN BARBERO, Horacio (1982): El dinero, objeto fundamental de la sanción penal: un estudio histórico de la moderna pena de multa (Madrid, Akal).

Del ROSAL BLASCO, Bernardo (2009): “HHacia el derecho penal de la postmodernidad?”, en: Revista Electrónica de Ciencia Penal y Criminología (Año 11, No 8), pp. 1-64. Disponible en: https://tinyurl.com/yfchs2cm [visitado el 22/02/2002].

SILVA SÁNCHEZ, Jesús María (2001): La expansión del Derecho Penal. $2^{\mathrm{a}}$ ed. (Madrid, Civitas).

TORRES ROSELL, Núria (2012): "Contenido y fines de la pena de localización permanente", en InDret ( $\left.\mathrm{N}^{\mathrm{o}} 1\right)$, pp. 1-31. Disponible en: https://tinyurl.com/ydntfnra [visitado el 22/02/2020].

VARONA GÓMEZ, Daniel (2019a): "Fundamentación y aplicación práctica de la suspensión de la pena de prisión", en: A.A.V.V., Cuadernos Penales José María Lidón (Bilbao, Deusto), pp. 229-258.

VARONA GÓMEZ, Daniel (2019b): "La suspensión de la pena de prisión en España. Razones de una historia de éxito", en: Revista Española de Investigación Criminológica (Año 17, $\mathrm{N}^{\circ}$ 10), pp. 1-37. Disponible en: https://tinyurl.com/ye4ym6ja [visitado el 26/04/2021].

WASIK, Martin; VON HIRSCH, Andrew (1988): "Non-custodial penalties and the principles of desert", en: The Criminal Law Review, pp. 555-572. 